\title{
МИГРАЦИЯ И ЗАМЕЩЕНИЕ ПОКОЛЕНИЙ В ЕВРОПЕ *
}

\author{
КРИС УИЛСОН, ТОМАШ СОБОТКА, ЛИ УИЛЬЯМСОН, ПАУЛЬ БОЙЛ
}

\begin{abstract}
Низкий уровень рождаемости в Европе уже на протяжении многих лет вызывает обеспокоенность и стимулирует важную дискуссию по вопросу, насколько миграция способна компенсировать рождаемость, находящуюся ниже уровня простого воспроизводства. Для оценки совместного влияния рождаемости, смертности и миграџии на замещение рождений и поколений предложень разнообразные показатели. Эти индикаторы основаны на различных моделях и гипотезах, и для расчетов некоторых из них требуются детальные статистические данные. Мы предлагаем простой способ, позволяющий оценить вклад миграџии в замещение рожденной когорты по мере ее взросления. Мы назвали эту меру индексом итогового замещения (ИИЗ). Он рассчитывается как отношение численности рожденной когорты девочек в определенном возрасте к средней численности материнских когорт в год рождения девочек. Мы приводим оченки ИИЗ для ряда Европейских стран, имеющих различные режимы замещения поколений. Мы показываем, что за последние десятилетия во многих странах Европь миграция стала ключевым фактором, определяюшим динамику населения.
\end{abstract}

Ключевые слова: замещение поколений, замещение населения, замещение рождений, замещающая миграция, индекс замещения.

\section{СПИСОК СОКРАЩЕНИЙ}

ИИЗ $(x)$ - индекс итогового замещения для когорты в возрасте $x$ лет (overall replacement ratio, $O R R)$

$K C P$ - коэффициент суммарной рождаемости (total fertility rate, $T F R$ )

$R_{0}$ - нетто-коэффициент воспроизводства (net reproduction rate, $N R R$ )

$R_{0}{ }^{*}$ - нетто-коэффициент воспроизводства с учетом миграции (net reproduction rate in the presence of migration, $N R R^{*}$ )

$R$ - брутто-коэффициент воспроизводства (gross reproduction rate, $G R R$ )

$S$ - коэффициент социального замещения (social replacement rate, $S$ )

$C R$ - комбинированное воспроизводство (combined reproduction, $C R$ )

$N B R R$ - нетто-коэффициент замещения рождений (net birth replacement ratio, $N B R R$ )

$C N M$ - завершенная нетто-миграция (completed net migration, $C N M$ )

$R M$ - индекс замещения с учетом миграции (replacement migration, $R M$ )

$G R E$ - брутто-коэффициент замещения (gross replacement rate, $G R E$ )

КРИС УИЛСОН, ШКОЛА ГЕОГРАФИИ И НАУК О ЗЕМЛЕ, СЕНТ-ЭНДРЮССКИЙ УНИВЕРСИТЕТ, ФАЙФ, ШОТЛАНДИЯ. ТОМАШ СОБОТКА, ВЕНСКИЙ ИНСТИТУТ ДЕМОГРАФИИ АВСТРИЙСКОЙ АКАДЕМИИ НАУК, ЦЕНТР ДЕМОГРАФИИ И ГЛОБАЛЬНОГО ЧЕЛОВЕЧЕСКОГО КАПИТАЛА, ВЕНА E-mail: tomas.sobotka@oeaw.ac.at

ЛИ УИЛЬЯМСОН, ШКОЛА ГЕОГРАФИИ И НАУК О ЗЕМЛЕ, СЕНТ-ЭНДРЮССКИЙ УНИВЕРСИТЕТ, ФАЙФ, ШОТЛАНДИЯ. ПАУЛЬ БОЙЛ, ШКОЛА ГЕОГРАФИИ И НАУК О ЗЕМЛЕ, СЕНТ-ЭНДРЮССКИЙ УНИВЕРСИТЕТ, ФАЙФ, ШОТЛАНДИЯ.

* ПЕРеВОД С АНГЛИЙСКОГО. Wilson C., T. SOBOtKA, L. Williamson, P. BOYLE (2013). MigRation AND INTERGENERATIONAL REPLACEMENT IN EUROPE // POPULATION AND DEVELOPMENT REVIEW. 39(1): 131-157. ПЕРЕВОД: ИЛЬЯ КАШНИЦКИЙ 


\section{МИГРАЦИЯ И ЗАМЕЩЕНИЕ ПОКОЛЕНИЙ В ЕВРОПЕ}

История рождаемости, смертности и миграции населения отражается в его возрастной структуре, демонстрирующей, в какой мере поколения замещают друг друга. Мы предлагаем достаточно легко рассчитываемый измеритель, который позволяет проследить, как эти три процесса определяют степень межпоколенного замещения. Поскольку смертность в возрастах, предшествующих окончанию репродуктивного периода, в большинстве европейских стран низкая, она играет очень ограниченную роль в процессе смены поколений. На замещение поколений в Европе главным образом совместно влияют процессы рождаемости и миграции.

Не только ученые, но и политики обеспокоены устойчиво низким уровнем рождаемости и наблюдаемой (или ожидаемой) депопуляцией во многих частях Европы. Правительства стран, Европейская Комиссия, а также Папа Бенедикт XVI отмечали, что низкая рождаемость в Европе является угрозой ее устойчивого социально-экономического развития. В то же время демографы пытались объяснить, почему уровень рождаемости настолько низок и что может быть сделано, чтобы изменить ситуацию [McDonald 2002; Demeny 2003; European Commission 2005; Vatican 2006; Vos 2009]. Демини, опираясь на глобальный демографический прогноз ООН 2001 г., предположил, что маргинализация населения Европы среди мирового населения - «свершившийся факт» [Demeny 2003: 14] и что «иммиграция вряд ли остановит депопуляцию в Европе» [Demeny 2003: 28]. Озабоченность многих наблюдателей вызывали официальные прогнозы Евростата, которые еще недавно предсказывали сокращение численности населения Европейского Союза начиная с 2025 г. ${ }^{1}$ В то же время исследователи отмечают значительную региональную дифференциацию европейской рождаемости, миграции и динамики численности населения, которая стала еще более заметной после коллапса государственного социализма в странах Центральной и Восточной Европы в 1989-1991 гг. [Sobotka 2008a; Avdeev et al. 2011].

Ведутся оживленные дискуссии о том, какую компенсаторную роль может играть миграция для стран с уровнем воспроизводства ниже простого замещения поколений. Доклад ООН «Замещающая миграция: является ли это решением для депопулирующих и стареющих обществ?» [United Nations 2000] спровоцировал бурную дискуссию в СМИ [Tarmann 2000], что привело к необычно резким официальным комментариям правительств многочисленных стран [Teitelbaum 2004]. Подобные взгляды часто шли в одном русле с ранее полученными результатами исследований, подтверждающими, что масштабная иммиграция политически неприемлема в Европе [Teitelbaum, Winter 1985]. Однако, отчасти благодаря вниманию средств массовой информации, вызванному докладом ООН, миграция постепенно стала восприниматься как важная структурная черта европейского общества, особенно после того, как многие страны Южной, Западной и Северной Европы в первом

\footnotetext{
${ }^{1}$ K примеру, базовый сценарий прогноза населения, выполненный Евростатом в 2005 г., предполагал, что численность населения ЕС начнет сокращаться в 2025 г. [Eurostat 2005, 2006]; при отсутствии миграции население Европы стало бы сокращаться уже в 2008 г. Двумя годами позже прогнозную оценку начала сокращения численности населения Европы отодвинули до 2036 г. [Eurostat 2008], в то время как в последней версии прогноза (2011 г.) пик численности населения Европы ожидается в 2040 г. [Eurostat 2011a]. 
десятилетии XXI века испытали значительный прирост численности населения, во многом обусловленный иммиграцией [Avdeev et al. 2011; VID 2012]. Коулмэн [Coleman 2006] утверждал, что значительная иммиграция в богатые страны приведет к необратимым изменениям в структуре их населения, представляющим собой «третий демографический переход». В этой связи возникает любопытный вопрос: знала ли хоть одна европейская страна иммиграцию в таких масштабах, чтобы ее можно было бы считать «замещающей миграцией» [Lesthaeghe 2000; Alho 2008; Bijak et al. 2008; Billari, Dalla Zuanna 2011]. Хотя некоторые доказательства подтверждают, что подобная ситуация имеет место во многих странах, четкого определения замещающей миграции нет, что делает несостоятельным обсуждение данного вопроса. Как заметил Бежо [Beaujot 2003: 1], «идея использования иммиграции “для сохранения населения” может быть применена не только для сохранения желаемых темпов прироста или предотвращения сокращения численности или старения населения, но и для сохранения регионального размещения, даже этнической, лингвистической и социальной структуры населения» (см. дискуссию по поводу замещающей миграции: [Ryder 1997; Lesthaeghe 2000; Coleman 2001; Espenshade 2001; Keely 2001; Beaujot 2003; Saczuk 2003]).

Одна из возможных трактовок замещающей миграции заключается в том, что иммиграция рассматривается как способ повышения фактического числа рождений до уровня, позволяющего устранить разрыв между фактическим числом рождений и их гипотетическим числом, соответствующим рождаемости, необходимой для простого воспроизводства населения. При таком подходе речь идет о «миграции, замещающей рождения». Другой подход рассматривает «мигращию, замещающую население». Он предполагает ответ на вопрос, способна ли иммиграция увеличивать размеры реальной или условной когорты населения по мере его старения таким образом, чтобы в конце концов компенсировать разницу между фактическим числом рождений и их гипотетическим числом, которое наблюдалось бы при рождаемости на уровне простого воспроизводства.

Сохраняющееся долгое время сочетание рождаемости ниже уровня замещения с замещающей миграцией может, в конечном счете, привести к стационарному населению, т.е. к населению с постоянной численностью и неизменной структурой при условии, что и коэффициенты смертности останутся неизменными [например, Espenshade et. al. 1982; Alho 2008]. Примеры подобных процессов, происходящих на протяжении десятилетий в Северной Италии, можно найти в работах Далла Зуаны [Dalla Zuanna 2006]. Наш вклад в этом направлении строится на предыдущих исследованиях [Sobotka 2008a; Dalla Zuanna 2008], где мы используем когортный показатель замещения населения - индекс итогового замещения (ИИЗ), который позволяет отслеживать изменения в размере когорты родившихся по отношению к размеру когорты их матерей. Мы фокусируем внимание на трендах ИИЗ для женских когорт от момента их рождения до пика репродуктивного возраста (определяемого здесь как 30 лет) и сравниваем наш показатель с некоторыми другими показателями замещения населения. ИИЗ - простая мера, хорошо сопоставимая с иными индикаторами, показывает, что во многих европейских странах миграция действительно замещает их собственное население. 


\section{ИЗМЕРЕНИЕ}

По мере того как многие богатые страны испытали большой приток мигрантов, оказывающих возрастающее влияние на рождаемость [Sobotka 2008b] и динамику численности населения [Eurostat 2011b; Sobotka 2009; Coleman 2006], стала очевидной необходимость переосмысления традиционных показателей оценки замещения населения [Calot, Sardon 2001; Smallwood, Chamberlain 2005]. Райдер [Ryder 1997] наглядно продемонстрировал на примере Канады, что при стабильно низкой рождаемости и значительной иммиграции традиционная модель стационарного населения, не учитывающая миграцию, более не описывает реальную ситуацию. Позже появилось еще несколько исследований, целью которых стала оценка интегрального воздействия рождаемости и миграции (а часто, для большей точности, и смертности) на перспективы населения.

Несмотря на очевидную значимость замещающей миграции, до сих пор ни одна мера не стала стандартной де-факто. Две группы факторов могут это объяснить. Во-первых, как уже отмечалось выше, не очевидно, какие населения или его характеристики должны быть замещены или поддержаны миграцией. Исследования показывают, что миграция не способна не только остановить, но даже существенно замедлить в наиболее развитых странах старение населения, измеряемое показателем нагрузки на трудоспособное население или другими показателями [United Nations 2000; Lesthaeghe 2000; Bijak et al. $2007]^{2}$. Тем не менее многократно показано, что миграция играет потенциально важную роль в поддержании численности трудоспособного населения, внося вклад в число рождений или в увеличение численности изначально небольших когорт, рожденных в период низкой рождаемости [Ryder 1997; United Nations 2000; Lesthaeghe 2000; Daguet 2002; Dalla Zuanna 2006; Preston, Wang 2007; Ediev et al. 2007; Alho 2008; del Rey Poveda, CebranVillar 2010; Billari, Dalla Zuanna 2011]. Во-вторых, миграция - это наиболее нестабильная и непредсказуемая компонента изменения населения. Учитывая эту нестабильность, долгосрочное прогнозирование замещения населения с использованием коэффициентов миграционного прироста, наблюдавшихся в каком-то конкретном году, проблематично. Чтобы избежать этой волатильности, мы используем меру, которая показывает кумулятивный эффект миграции на размер когорты родившихся.

\footnotetext{
2 Тем не менее Алхо [Alho 2008: 649] предполагает, что в населениях, способных принимать значительные потоки мигрантов, этот прирост может «значительно замедлить процесс старения населения». Более ранние модели влияния миграции на численность и структуру населения США Коула [Coale 1986] показали, что иммиграция может изменять возрастной состав населения, особенно в странах с низкой и очень низкой рождаемостью. К примеру, прогноз численности населения до 2100 г., предполагая различные уровни рождаемости и два сценария миграции (нулевая миграция и миграционный прирост на уровне 700 тыс. человек ежегодно), показал, что при значительном притоке мигрантов и коэффициенте суммарной рождаемости $(\mathrm{KCP})=1,4$, доля пожилых людей $(65+)$ будет к 2100 г. такой же, как в населении, закрытом от миграции при КСР = 1,6 [Coale 1986: 208, таблица 2]. Недавнее обсуждение этого вопроса в журнале Genus показывает, что в регионах Италии с низкой рождаемостью в краткосрочной перспективе миграция изменяет траекторию старения населения, а в долгосрочной - влияние миграции не столь высоко [de Santis 2011; Gesano, Strozza 2011].
} 
Как и любые традиционные демографические индикаторы, меры замещения рождений и населения могут быть рассчитаны для календарных периодов и когорт [Calot, Sardon 2001], но возможно и совмещение обоих подходов, что и демонстрирует растущее число исследований по замещению поколений. Больше внимания уделено показателям замещения рождений, анализирующим наблюдаемое или гипотетическое воспроизводство населения с учетом миграции. Показатели замещения рождений для календарного периода восходят к работе Хирениуса [Hyrenius 1951], который предложил коэффищиент социального замещения $(S)$, включающий миграцию как эквивалент традиционного неттокоэффициента воспроизводства $\left(R_{0}\right)$. Более новые показатели замещения рождаемости для календарного периода - нетто-коэффициент воспроизводства с учетом миграции $\left(R_{0} *\right)$ [Preston, Wang 2007] и комбинированное воспроизводство (CR) [Ediev et al. 2007, 2012]. Последний, кстати, также направлен на учет более высокой рождаемости среди мигрантов ${ }^{3}$. Показатели замещения рождений для календарного периода не должны быть гипотетическими синтетическими показателями условных поколений: они могут также соотносить размер "поколения детей", измеряемый числом девочек, родившихся в году $\boldsymbol{t}$, со средним размером "материнского поколения" в момент рождения. Так, например, рассчитывается нетто-коэффищиент замещения рождений (NBRR), предложенный Ортегой и дель Рей Поведой [Ortega, del Rey Poveda 2007; del Rey Poveda, Cebran-Villar 2010]. Когортные меры замещения рождаемости также могут быть рассчитаны (например, [Hyrenius 1951; Calot, Sardon 2001]).

В отличие от индикаторов замещения рождений показатели замещения населения не имеют отношения к биологическому воспроизводству. Более того, миграция выступает в роли фактора, компенсирующего низкий уровень биологического воспроизводства, и главный вопрос: как иммиграция изменяет численность различных рожденных когорт как до достижения ими ключевых репродуктивных возрастов, так и на протяжении всей жизни. Принципиальное отличие показателей замещения рождений от индикаторов замещения населения может быть проиллюстрировано с помощью гипотетического примера населения с нулевой рождаемостью и масштабной иммиграцией. В этом населении замещение рождений будет равно нулю, а замещение населения при этом может быть относительно высоким, что приведет к стационарному населению: по достижении определенного возраста население полностью замещает себя за счет миграции.

Основанный исключительно на показателях для календарного периода индикатор замещения населения миграцией на протяжении всего жизненного цикла был предложен Эдиевым и соавторами [Ediev et al. 2007, 2012] и получил название завершенной неттомиграции $(C N M)^{4}$. Когортный подход, при котором численность «когорты детей» по мере их взросления сравнивается с зафиксированной численностью «материнской когорты» в момент рождения детей, был предложен и развит в работах Далла Зуаны [Dalla Zuanna 2008]

\footnotetext{
3 Эдиев и соавторы $[2007,2012]$ считают на основании своего сравнительного исследования, что рождаемость мигрантов превосходит рождаемость коренного населения на $25 \%$.

4 Алхо [Alho 2008: рисунок 2] рассчитал соотношения чистой миграции и числа рождений и показал различные комбинации КСР и чистой миграции, необходимые для поддержания стационарного населения в четырех странах Северной Европы. Различные возрастные профили рождаемости и миграции означают, что эти «компромиссные значения» специфичны для каждой страны.
} 
(см. также [Billari, Dalla Zuanna 2011]) и Соботки [Sobotka 2008a]. Индекс замещеения с учетом миграџии (RM) Далла Зуаны позволяет сравнивать численность двух поколений (когорты матерей и детей) в одном и том же возрасте, в то время как брутто-коэффициент замещения (GRE), разработанный Соботкой [Sobotka 2008a], совмещает оценку биологического воспроизводства (брутто-коэффициент воспроизводства в год рождения когорты) для календарного периода с данными о последующем изменении численности когорты, чтобы оценить замещение для каждой когорты5

В нашем исследовании внимание сосредоточено на замещении населения. Мы предлагаем простой метод для оценки, в какой мере миграция меняет уровень замещения когорты родившихся по мере ее старения. Чтобы избежать проблем, связанных с оценкой рождаемости, смертности и миграции, мы полностью игнорируем все демографические процессы и проводим прямое сравнение численности различных возрастных групп. Мера, используемая здесь, ИИЗ, рассчитывается как отношение числа рожденных девочек ${ }^{6}$ оценочной средней численности материнской когорты в год рождения когорты девочек. Мы оперируем женскими когортами, чтобы обеспечить сравнение с традиционными индексами рождаемости, однако аналогичные расчеты могут быть применены как к мужскому, так и ко всему населению. По интерпретации, расчетам и целям ИИЗ сильно напоминает показатели $R M$ Далла Зуаны и $G R E$, предложенный Соботкой. Прямое сравнение GRE и ИИЗ показывает, что гораздо проще рассчитываемый ИИЗ дает практически идентичный результат [Wilson et al. 2010] (см. также далее). Мы предпочитаем ИИЗ, поскольку для его расчета требуются только данные о возрастной структуре населения, в то время как для расчета $G R E$ помимо возрастной структуры необходимы данные о коэффициенте суммарной рождаемости (КСР) или брутто-коэффициенте воспроизводства $(R)$. И хотя такое упрощение в расчетах не столь значимо для современной статистики европейских стран, для исторических данных и некоторых развивающихся стран, когда возрастная структура населения известна, а возрастные коэффициенты рождаемости нет, ИИЗ имеет значительные преимущества. Простота данных, необходимых для расчета ИИЗ, означает, что этот показатель может быть рассчитан для любого населения, о возрастной структуре которого у нас есть данные за достаточно длительный период. Это также означает, что показатель может быть рассчитан для малых территорий или же групп населения в зависимости от их социально-экономических, этнических или

\footnotetext{
5 В дополнение к показателям замещения населения для оценки влияния миграции на население были использованы другие способы измерения, включающие прогнозы и моделирование. Традиционно большое внимание сосредоточено на модели стабильного населения и определении постоянного потока иммигрантов, необходимого для обеспечения стабильного населения в длительной перспективе при наблюдаемых или прогнозируемых уровнях рождаемости, не обеспечивающих замещения населения (см., например, [Соаlе 1986]). Коулмэн [Coleman 2009] соотнес значения чистой миграции за календарный период с числом рождений и показал, что в некоторых странах Европы чистая иммиграция достигает 50\% от числа рожденных детей (см. также [Alho 2008]). На основании своих прогнозов для 15 стран ЕС Лутц и Щербов утверждают, что «эффект от 100 тысяч дополнительных иммигрантов в год равносилен увеличению КCP на 0,1 , [Lutz, Scherbov 2003: 11-12].

${ }^{6}$ Обратите внимание, что в нашем подходе «когорта детей» определена исключительно по общему году рождения и общей стране проживания в возрасте $x$ лет, для которого рассчитывается ИИЗ. Таким образом, наша «когорта детей» состоит из «коренных» женщин и иммигранток из различных стран, прибывших в изучаемую страну до достижения возраста $x$ лет.
} 
любых других характеристик. Однако когда возрастная структура женщин в репродуктивных возрастах быстро меняется, $G R E$ может дать более надежную оценку.

ИИЗ в данном исследовании рассчитывается следующим образом.

Обозначим через $F(a, c, t=c+a)$ численность женской когорты в возрасте $a$, рожденной в году $c$ (год наблюдения $c+a)$. Эта когорта («когорта дочерей») состоит из женщин, доживших в данной стране до возраста $a$, а также из иммигранток, прибывших до возраста $a$. Матери этих женщин («материнская когорта») рождены в течение периода, грубо отцентрированного вокруг года $c-g$, где $g$ - средняя длина поклонения, за которую можно грубо принять средний возраст материнства. Мы обозначаем верхние и нижние границы основных репродуктивных возрастов материнской когорты в году $c$ переменной $x$ $=\left(m_{1}, m_{2}\right)$ и принимаем возрастной интервал от $m_{1}$ до $m_{2}$ равным $n$. Среднюю численность материнских когорт, рожденных в годы $c-x$ и наблюдаемой в год $t=c$, дающих жизнь когорте года рождения $c$, можно рассчитать по формуле:

$$
\sum_{x=m_{1}}^{m_{2}} \frac{F(x, c-x, t=c)}{n} ; n=m_{2}-m_{1}+1
$$

Мы определяем ИИЗ для когорты $c$ в возрасте $a$ следующим образом:

$$
\operatorname{OPR}(a, c)=\frac{F(a, c, t=c+a)}{\sum_{x=m_{1}}^{m_{2}} \frac{F(x, c-x, t=c)}{n}}
$$

Определение материнской и дочерней когорт, используемое в расчетах ИИЗ, схематично отображено на сетке Лексиса (рисунок 1). Обратите внимание, что размер материнской когорты "заморожен" в году $c$ (году рождения их дочерей). Размер же дочерней когорты изменяется в зависимости от возраста $a$, для которого рассчитан ИИЗ. ИИЗ, равный единице, означает точное замещение когорт к возрасту а вследствие рождений или последующей миграции ${ }^{7}$.

\footnotetext{
${ }^{7}$ Расчет ИИЗ учитывает не размеры иммиграции как таковой, а чистую миграцию, разницу между эмиграцией и иммиграцией.
} 


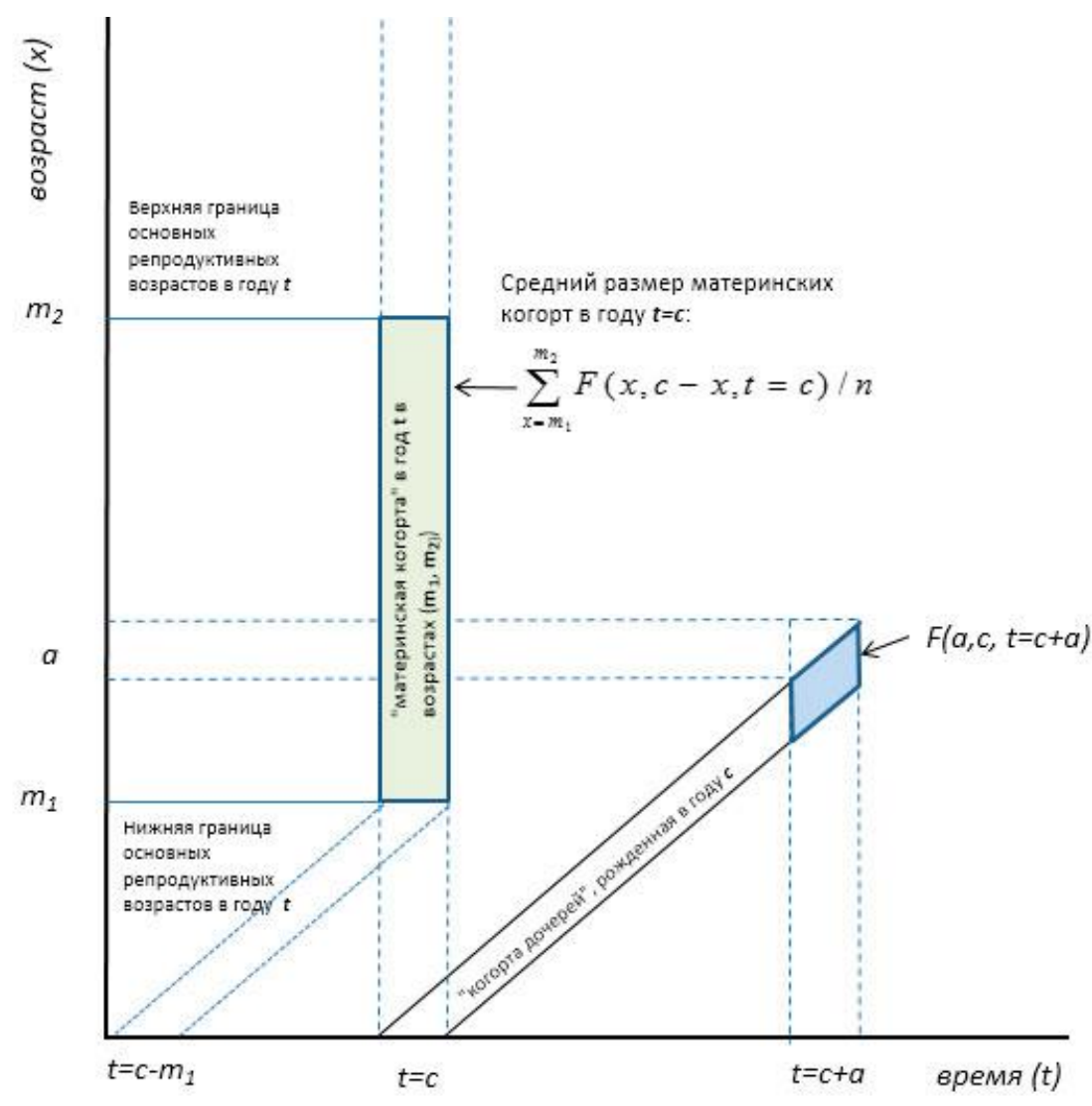

\section{Рисунок 1. Диаграмма Лексиса, показывающая дочернее и материнское поколения, используемые при расчетах индекса итогового замещения}

В данной статье мы принимаем $m_{1}$ и $m_{2}$, равные 20 и 35 годам, что примерно соответствует границам основного интервала репродуктивных возрастов в большинстве стран в 1970-е и 1980-е годы ${ }^{8}$. Разумеется, можно использовать иные границы возрастов и иные определения средней численности материнских когорт, но проведенный нами предварительный анализ показывает, что для изучаемых здесь европейских стран лучше всего подходит именно интервал 20-35 лет (см. Приложение). За редким исключением, ИИЗ не сильно реагирует на изменение определения материнской когорты до тех пор, пока выбранный интервал достаточно велик для устранения эффектов краткосрочных подъемов и спадов рождаемости 9 . Для изучения исторических данных, а также для современных населений европейских стран (когда наблюдается существенное откладывание рождений по сравнению с 1970-1980-ми годами) уместнее использование более широкого возрастного интервала (20-40 или 20-45 лет, см. Приложение). При расчете ИИЗ для населений, в которых происходит стремительная трансформация возрастной структуры (в странах вроде

\footnotetext{
8 Для оценки средней численности женских когорт в году $\mathrm{t}=\mathrm{c}$ мы используем возрастное распределение женского населения по состоянию на 1 января двух смежных лет, $\mathrm{t}$ и $\mathrm{t}+1$.

9 ИИЗ может значительно отличаться от показателей, более точно определяющих размер материнской когорты, в следующих случаях: 1) когда выбранные границы основных репродуктивных возрастов плохо соответствуют действительному возрастному профилю рождаемости; 2) когда рождения концентрируются в очень узком возрастном интервале; 3) когда наблюдаются внезапные скачки численности анализируемых когорт. К примеру, сочетание второго и третьего факторов привело к значительному расхождению между ИИЗ и более точно определенным показателем брутто-воспроизводства населения в когортах конца 1960-70х годов в Словакии (не приведено в данной статье; расчеты могут быть предоставлены по запросу).
} 
Китая или Ирана, где снижение уровня рождаемости происходило особенно быстро), лучше использовать более точное определение материнского поколения. Поскольку наш основной исследовательский интерес заключается в изучении замещения материнской когорты в населении с низкой рождаемостью и положительным балансом миграции, мы отслеживаем изменение ИИЗ до тех пор, пока их дочери сами не становятся матерями. В этих возрастах смертность практически не влияет на выживаемость когорты, что делает изменения ИИЗ практически полностью зависящими от уровня рождаемости и замещающей миграции.

\section{ИСПОЛЬЗОВАНИЕ ИИЗ: ДАННЫЕ, ИЛЛЮСТРАЦИИ И ИНТЕРПРЕТАЦИЯ}

Основной источник данных, использованный для расчета ИИЗ, - база данных Евростата, доступная в режиме онлайн [Eurostat 2012]. Для Ирландии мы дополнили данные Евростата оценками численности женского населения из базы данных Human Mortality Database [2012b]. Исторические данные по Швеции взяты из Human Fertility Database [2012] и Human Mortality Database [2012a]. Национальные статистические ведомства всех стран Европейского союза ежегодно оценивают численность своего населения по однолетним возрастным группам. Эти данные впоследствии собираются, обрабатываются и публикуются Евростатом (вместе с данными по другим европейским странам) на их официальном сайте [Eurostat 2012]. Важно понимать, что часто - эти оценочные данные, они могут отличаться от "истинной" численности населения. Страны по-разному рассчитывают наличное (постоянное) население. Некоторые, в основном Скандинавские страны, а также Австрия, Эстония, Голландия и Словения используют детальные и точные регистры населения, в то время как другие страны полагаются на текущий учет демографических событий и проходящие, как правило, раз в десятилетие переписи населения, которые могут быть несовершенными. Поэтому используемые нами данные представляют собой наилучшие гипотезы национальных статистических ведомств, на которые могут влиять различия в определении постоянного населения и точности учета иммиграции и эмиграции. И хотя некоторые статистические ведомства указывают на приблизительный характер своих оценок, очевидно, что эти лучшие гипотезы в основном обеспечивают максимально правдоподобные данные о демографической структуре населения стран Евросоюза. Наибольшее беспокойство вызывает надежность оценок в некоторых странах Восточной Европы, где наблюдалась масштабная эмиграция с 1989 г. и где не столь хорошо развита инфраструктура национальных статистических служб. В некоторых случаях могут отсутствовать данные за определенные годы, либо в данных могут наблюдаться очевидные несоответствия. В большинстве же случаев данные Евростата отражают основные тренды в каждой стране.

Ниже мы приводим несколько эмпирических иллюстраций преимуществ и ограничений ИИЗ. Например, мы можем сравнить в динамике численность когорты 1980 года рождения с численностью женщин в основных детородных возрастах в 1980 г. Используя ежегодные оценки численности когорты 1980 года рождения, мы можем проследить влияние миграции на уровень ее замещения. При отсутствии миграции это соотношение, приблизительно равное нетто-коэффициенту воспроизводства населения в 1980 г., сохранится практически неизменным на протяжении первых десятилетий жизни 
когорты. Затем это соотношение будет снижаться по мере того, как смертность будет сокращать численность когорты. При наличии же значительной иммиграции соотношение будет увеличиваться с увеличением возраста когорты. Увеличение будет происходить в возрастах наибольшей иммиграционной активности. И наоборот, эмиграция будет снижать это соотношение по мере взросления когорты.

Так как большинство мигрантов переезжают в молодых трудоспособных возрастах, иммиграция приводит к увеличению «когорты детей», особенно в возрасте от 15 до 40 лет. Этот возрастной профиль мигрантов может очень сильно изменить численность каждой когорты до достижения ими среднего возраста деторождения. Например, вполне возможна ситуация, когда каждая когорта достигает уровня простого замещения, в то время как большинство традиционных показателей возрастной структуры (такие, как традиционная возрастная пирамида) указывают на поразительный дефицит относительного размера когорт во всех детских возрастах.

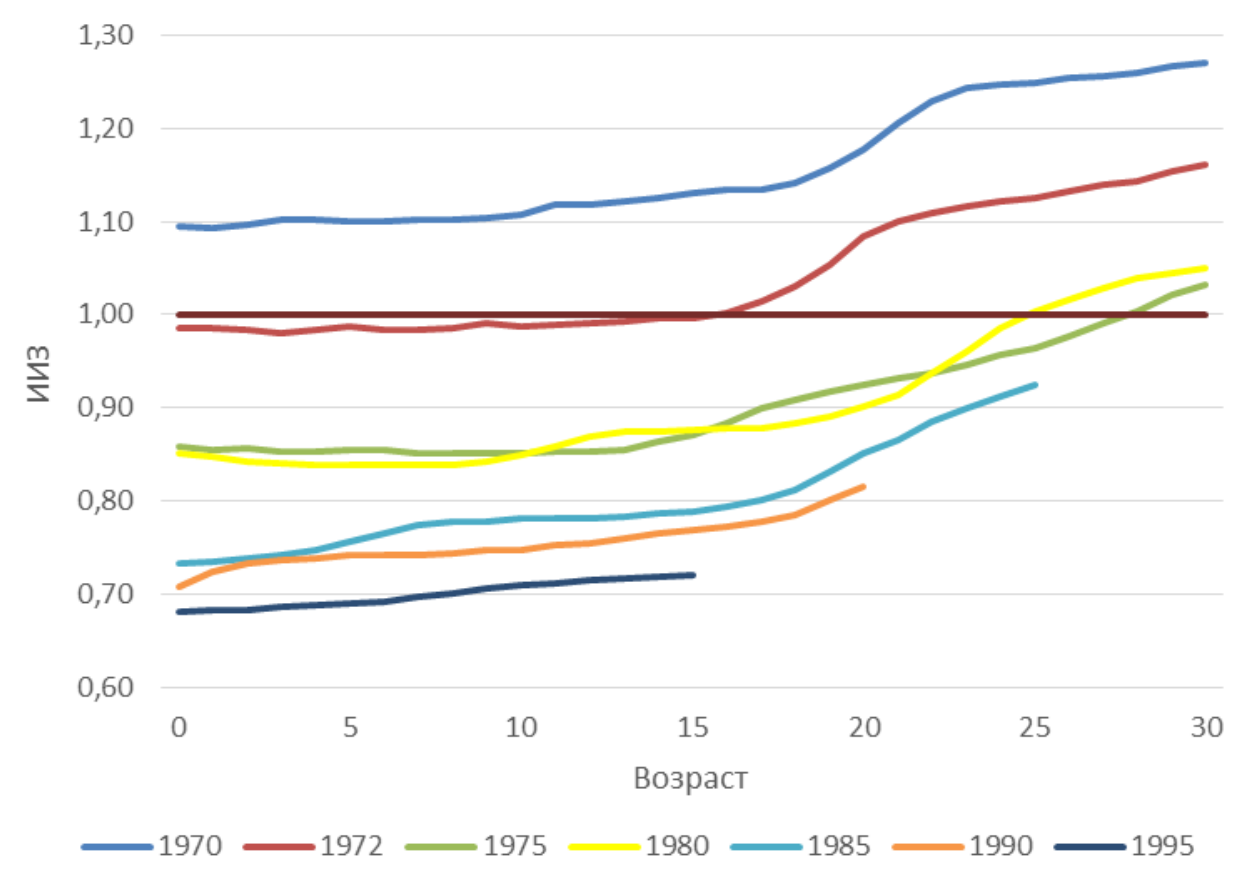

\section{Рисунок 2. Индекс итогового замешения для некоторых когорт Австрии 1970-1995 годов рождения}

Источник: Рассчитано по данным Евростата [Eurostat 2012].

В качестве иллюстрации, рисунок 2 отражает динамику ИИЗ для некоторых когорт женщин, родившихся в Австрии с 1970 по 1995 гг. Соотношения рассчитываются по данным Евростата [Eurostat 2012] о ежегодной оценке однолетней возрастной структуры населения с 1969 по 2011 г. Самая верхняя линия (когорта 1970 г.) изначально лежит выше 1 (уровень простого воспроизводства) и поднимается на протяжении 30 лет жизни когорты. 1972 г. был последним, когда $К C P$ для условного поколения в Австрии был выше уровня простого воспроизводства. Все последующие когорты стартуют ниже 1. На протяжении первых 10-15 лет жизни изменения численности когорт не очень значительные; серьезный рост начинается с поздних подростковых возрастов, когда существенный приток иммигрантов увеличивает численность когорты. Мы наблюдаем каждую когорту лишь до 
возраста, достигнутого ею к 2011 г., но очевидно, что все когорты, достигшие 30-летнего рубежа, превысили уровень простого воспроизводства задолго до достижения этого возраста. Видимо, похожий сценарий ждет и последующие когорты.

Таблица 1. Избранные индикаторы воспроизводства населения, замещения рождений и замещения населения

\begin{tabular}{|c|c|c|c|c|c|}
\hline \multirow{2}{*}{ Индикатор } & \multirow{2}{*}{ Автор } & \multirow{2}{*}{ Тип индикатора } & \multicolumn{3}{|c|}{ Включенные компоненты } \\
\hline & & & рождаемость & смертность & миграция \\
\hline $\begin{array}{l}\text { Нетто- } \\
\text { коэффициент } \\
\text { воспроиз- } \\
\text { водства }\left(R_{0}\right)\end{array}$ & $\begin{array}{l}\text { Кучинский } \\
\text { [Kuczynski 1928] }\end{array}$ & $\begin{array}{l}\text { Синтетический, для } \\
\text { календарного } \\
\text { периода, измеряет } \\
\text { воспроизводство } \\
\text { населения }\end{array}$ & $\begin{array}{l}\text { да - для } \\
\text { кален- } \\
\text { дарного } \\
\text { периода (t) }\end{array}$ & $\begin{array}{l}\text { да - для } \\
\text { кален- } \\
\text { дарного } \\
\text { периода (t) }\end{array}$ & нет \\
\hline $\begin{array}{l}\text { Нетто- } \\
\text { коэффициент } \\
\text { воспроиз- } \\
\text { водства с } \\
\text { учетом } \\
\text { миграции }\left(R_{0} *\right) \\
\end{array}$ & $\begin{array}{l}\text { Престон и Ванг } \\
\text { [Preston, Wang } \\
\text { 2007], похожая } \\
\text { идея у Хирениуса } \\
\text { [Hyrenius 1951] }\end{array}$ & $\begin{array}{l}\text { Синтетический, для } \\
\text { календарного } \\
\text { периода, измеряет } \\
\text { замещение } \\
\text { рождений }\end{array}$ & $\begin{array}{l}\text { да - для } \\
\text { кален- } \\
\text { дарного } \\
\text { периода (t) }\end{array}$ & $\begin{array}{l}\text { да - для } \\
\text { кален- } \\
\text { дарного } \\
\text { периода (t) }\end{array}$ & $\begin{array}{l}\text { да - для } \\
\text { кален- } \\
\text { дарного } \\
\text { периода } \\
\text { (t) }\end{array}$ \\
\hline $\begin{array}{l}\text { Комбини- } \\
\text { рованное } \\
\text { воспроиз- } \\
\text { водство }(C R)\end{array}$ & $\begin{array}{l}\text { Эдиев и соавторы } \\
\text { [Ediev et al. 2007, } \\
\text { 2012] }\end{array}$ & $\begin{array}{l}\text { Синтетический, для } \\
\text { календарного } \\
\text { периода, измеряет } \\
\text { замещение } \\
\text { рождений }\end{array}$ & $\begin{array}{l}\text { да - для } \\
\text { календарного } \\
\text { периода }(\mathrm{t}) ; \\
\text { учитываются } \\
\text { различия в } \\
\text { рождаемости } \\
\text { местных } \\
\text { женщин и } \\
\text { мигранток }\end{array}$ & да - & \\
\hline $\begin{array}{l}\text { Нетто- } \\
\text { коэффициент } \\
\text { замещения } \\
\text { рождений } \\
(N B R R)\end{array}$ & $\begin{array}{l}\text { Ортега и дель Рей } \\
\text { Поведа } \\
\text { [Ortega, } \\
\text { del Rey } \\
\text { Poveda 2007]; дель } \\
\text { Рей Поведа и } \\
\text { Кебран-Виллар [del } \\
\text { Rey Poveda, } \\
\text { Cebran- } \\
\text { Villar 2010] }\end{array}$ & $\begin{array}{l}\text { Квази-периодный, } \\
\text { измеряет замещение } \\
\text { рождений } \\
\text { (наблюдаемое } \\
\text { периодное число } \\
\text { рождений } \\
\text { сравнивается с } \\
\text { численностью } \\
\text { материнской } \\
\text { когорты в момент } \\
\text { их рождения) }\end{array}$ & $\begin{array}{l}\text { для } \\
\text { календарного } \\
\text { периода (t) }\end{array}$ & да - & \\
\hline $\begin{array}{l}\text { Индекс } \\
\text { итогового } \\
\text { замещения } \\
\text { (ИИЗ) }\end{array}$ & $\begin{array}{l}\text { Уилсон и соавторы } \\
\text { [Wilson et al. 2010, } \\
\text { данная статья]; } \\
\text { похожие идеи у } \\
\text { Далла-Зуанны } \\
\text { [Dalla- Zuanna } \\
\text { 2008] и Cоботки } \\
\text { [Sobotka } \\
\text { 2008a] }\end{array}$ & $\begin{array}{l}\text { Квази-когортный, } \\
\text { измеряет замещение } \\
\text { населения (когорта, } \\
\text { рожденная в год } t \text {, } \\
\text { последовательно } \\
\text { изменяется под } \\
\text { воздействие } \\
\text { миграции) }\end{array}$ & $\begin{array}{l}\text { для } \\
\text { календарного } \\
\text { периода (t) }\end{array}$ & & \\
\hline
\end{tabular}

Чтобы продемонстрировать отличие ИИЗ от других показателей воспроизводства и замещения населения, мы сравниваем его динамику для шведских когорт 1950-1980 годов рождения с традиционным нетто-коэффициентом воспроизводства для календарного периода, нетто-коэффициентом воспроизводства с учетом миграции и с неттокоэффициентом замещения рождений для 1950-2010 гг. ${ }^{10}$ Таблица 1 и рисунок 3

10 Для расчета NBRR мы использовали формулы 6, 7 и 8 из работы [del Rey Poveda, Cebran-Villar 2010]; при 
демонстрируют различия в исходных допущениях и в эмпирических результатах, которые дают эти меры. Показатель $R_{0}$, измеряющий биологическое воспроизводство однолетней условной когорты, упал ниже уровня простого воспроизводства в 1968 г. и, за исключением 1991-1992 гг., оставался ниже этого уровня, колеблясь синхронно с изменением показателей рождаемости для календарных периодов в Швеции [Olah, Bernhardt 2008]. $R_{0}$ * вдобавок учитывает влияние миграции на уровень гипотетического замещения рождений в рамках той же конструкции условных поколений и рассчитывается на основе наблюдаемых показателей рождаемости и миграции в каждом году. Поскольку миграции также свойственны значительные флуктуации, скорректированный на миграцию показатель $R_{0}$ * демонстрирует еще большую нестабильность в сравнении с $R$, достигая минимального значения 0,79 в 1983 г. и максимального 1,35 в 2009 г.

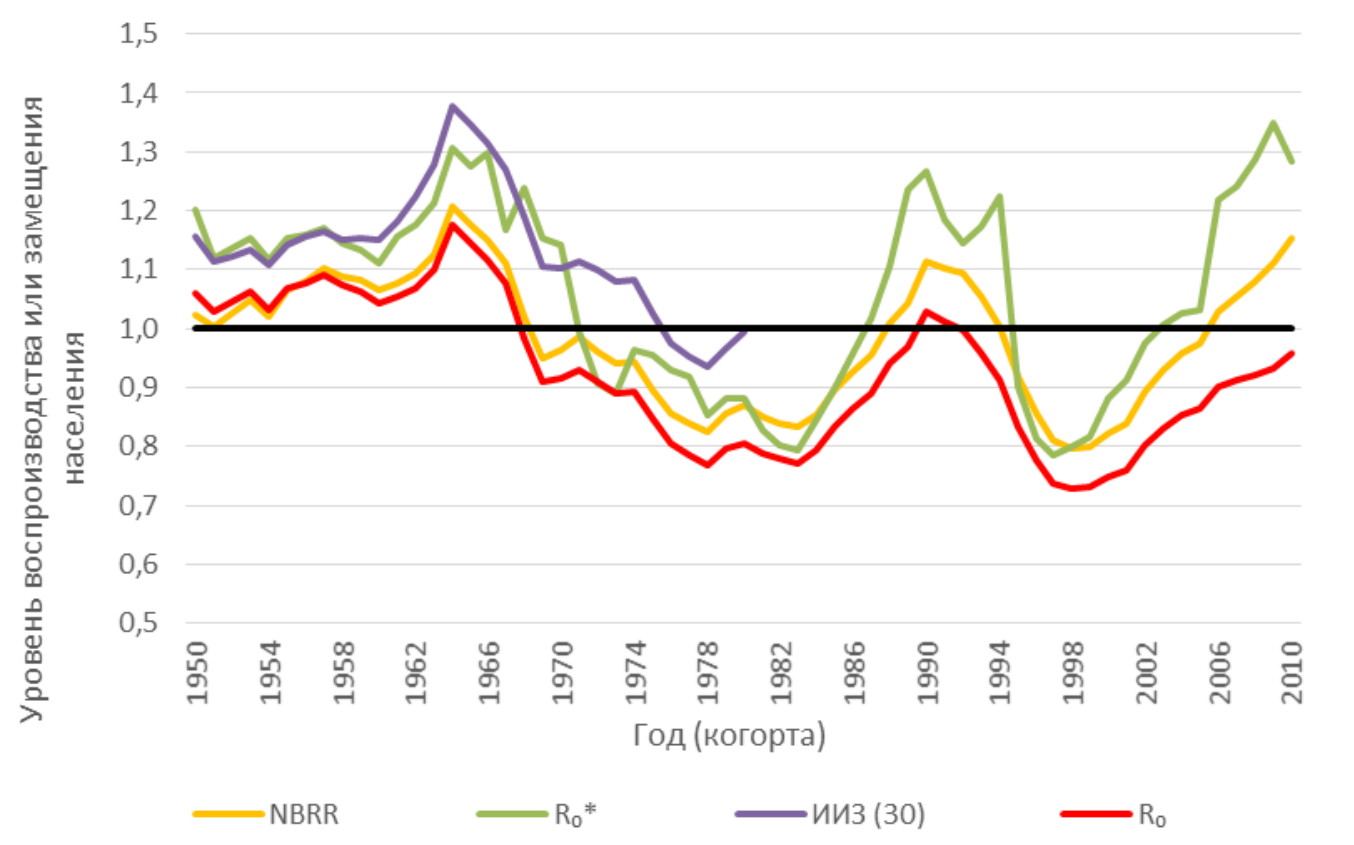

\section{Рисунок 3. Индекс итогового замещения (когорты 1950-1980 годов рождения в возрасте 30 лет) в сравнении с традиционным нетто-коэффициентом воспроизводства и двумя показателями замещения рождений и замещения населения; Швеция, 1950-2010}

Примечание: Авторы благодарят Криштофа Земана (Kryštof Zeman) за расчеты показателей, приведенных здесь (за исключением $R_{0} *$ ).

Источники: В расчетах использованы данные Hитап Fertility Database [2012] - возрастные коэффициенты рождаемости за 1900-2010 г2.; Евростата [Eurostat 2012] - возрастной состав женского населения за 1960-2011 г2.; Human Mortality Database [2012a] - число живорожденных детей по полу за 1900-2010 г2.; возрастной состав женского населения за 1960-2011 г2.; таблицы смертности для женского населения за 1900-2010 г2.

расчете $R_{0}$ * мы опирались на расчеты таблиц смертности, приведенные в Приложении 1 статьи [Preston, Wang 2007], и адаптировали их к однолетнему формату данных (авторы использовали 5-летние периоды в своей работе). 
Схожие тренды, но более стабильные, дает показатель $N B R R$, являющийся индикатором замещения рождений; он рассчитывается как отношение наблюдаемого числа рождений («когорта дочерей») к численности «материнской когорты» в момент ее рождения. Это квази-периодный показатель, который, подобно $R$ и $R_{0}$, измеряет замещение рождений в определенном календарном году. Но он также учитывает миграционную историю всех когорт матерей репродуктивного возраста до этого года. В течение анализируемого периода кривая $N B R R$ был относительно близка к кривой $R_{0}$ вплоть до 1970 г., что свидетельствует о невысоком влиянии миграции на число рожденных детей в Швеции в 1950-1970 годах (однако стоит отметить произошедшее в 1956 г. пересечение кривых, когда миграция начала оказывать положительное (до этого оно было отрицательным) влияние на наблюдаемое число рождений). После 1970 г. иммиграция стала значимым фактором роста числа родившихся в Швеции как вследствие увеличения за счет миграции численности материнских когорт, так и вследствие более высокой рождаемости мигрантов [Sobotka 2008b]. В результате $N B R R$ превзошел показатели $R_{0}$, особенно начиная с 2004 г., когда разница между этими двумя показателями превысила 0,1 в абсолютном измерении. Если рассматривать весь изучаемый период, то $R_{0}$ показывает, что биологическое воспроизводство шведских женщин опустилось в 1968-2010 гг. на 14\% ниже уровня простого воспроизводства (в среднем $N R R=0,86$ ). В то же время оба показателя замещения рождений дают близкую к простому замещению оценку числа рождений в Швеции (в среднем, $\left.R_{0}^{*}=1,01 ; N B R R=0,96\right)$. Различия между приведенными тремя показателями особенно значительны в самые последние годы, когда $N B R R$ и в особенности $R_{0}$ * указывают на высокий уровень замещения рождений, отражая увеличение размеров когорт при рождении.

И наконец, ИИЗ - когортный показатель, который совмещает оценку уровня биологического воспроизводства в год рождения когорты (сопоставимо с периодом, для которого рассчитываются $R_{0}, R_{0}$ * и $N B R R$ ) с последующим учетом изменения численности когорты за счет миграции. Поскольку уровень рождаемости в году рождения когорты обычно влияет на ИИЗ в значительно большей степени нежели последующая миграция, мы сравниваем ИИЗ(30) с рассчитанными для календарного периода показателями замещения рождений и воспроизводства в году рождения когорты, а не сдвигаем его на число лет, соответствующих возрасту, для которого рассчитан ИИЗ. Для когорт 1970-1979 годов рождения ИИЗ в возрасте 30 лет значительно превосходил соответствующий уровень биологического воспроизводства и замещения рождений. В 1978 г., когда $R_{0}$ достиг минимального значения 0,77 , а два показателя замещения рождений также достигли низких оценок - 0,83 (NBRR) и $0,85\left(R_{0}^{*}\right)$, ИИЗ достиг значения в 0,94 , отражая тот факт, что к 30 годам миграция увеличила численность когорты женщин, рожденных в 1978 г., практически до численности их "материнской когорты" в 1978 г. Наблюдаемые тренды позволяют предположить, что ИИЗ в возрасте 30 лет в Швеции достиг своего минимального значения в послевоенное время именно в когорте 1978 года рождения и, вероятно, будет оставаться выше показателя замещения населения для когорт, рожденных после 1981 г. Как мы показываем в нашем анализе, этот тип воздействия миграции на замещение населения характерен не только для Швеции. 


\section{РеЗУЛьтАТы}

Рисунок 4 отражает изменение ИИЗ в зависимости от возраста для 15 стран ЕС вместе (т.е. ЕС до расширения 2004 и 2007 годов), на рисунке 5 представлена та же информация отдельно для 12 стран Европы. Выбраны когорты 1972-1995 годов рождения, усеченные до возрастного интервала 18-35 лет; наиболее свежие данные - на 1 января 2011 г. Мы выбрали именно эти когорты, поскольку традиционный показатель рождаемости $(K C P)$ для ЕС-15 впервые упал ниже уровня простого воспроизводства в когорте 1974 г. Поскольку значительная миграция начинается только с поздних подростковых возрастов, когорты, рожденные после 1990 г., как правило, еще не успели испытать значительное влияние иммиграции.

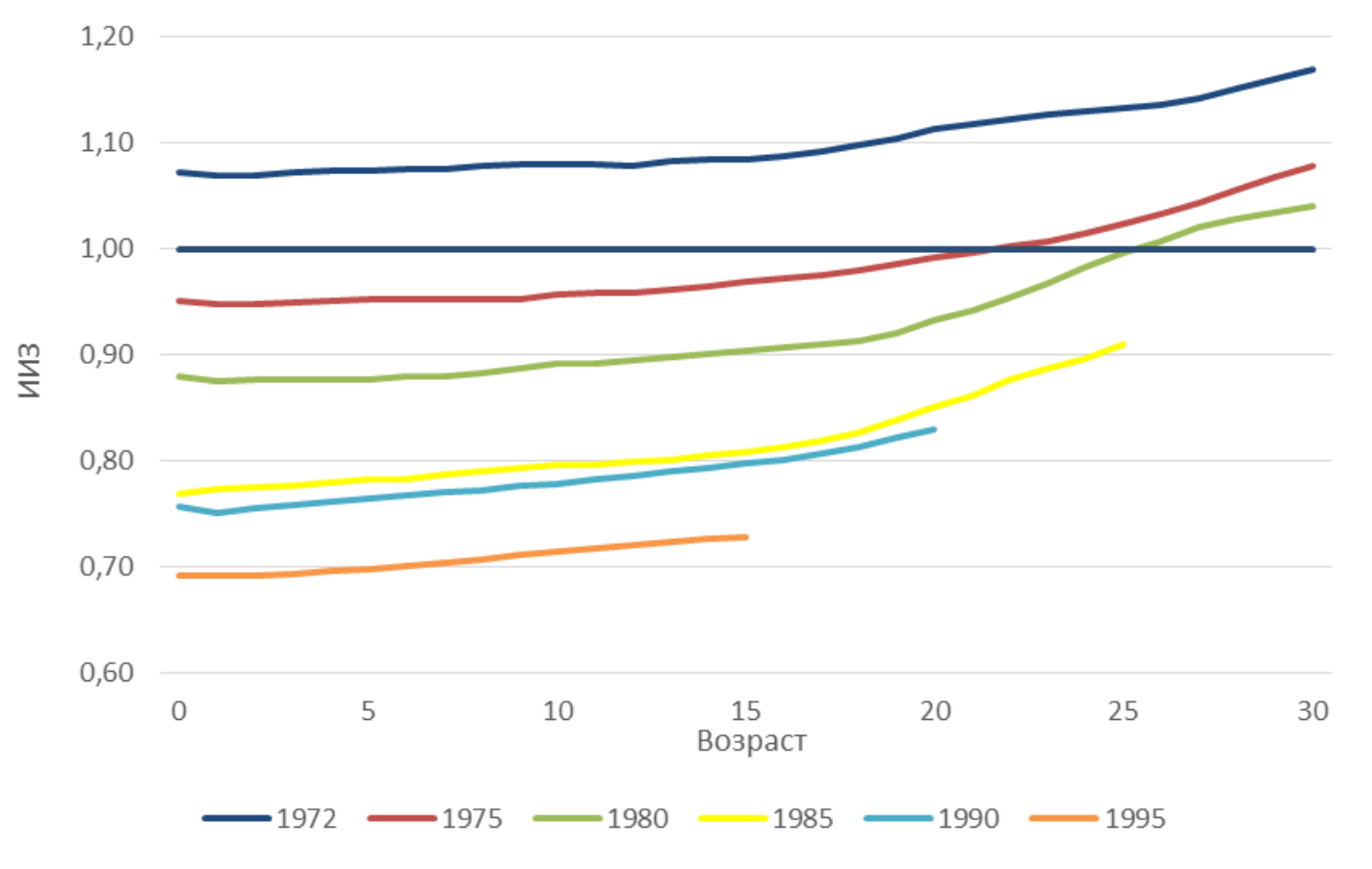

\section{Рисунок 4. Индекс итогового замещения по возрасту для Европейского Союза (EC-15), некоторые когорты 1972-1995 годов рождения}

Примечание: страны ЕС-15: Австрия, Бельгия, Дания, Финляндия, Франция, Германия, Греция, Ирландия, Италия, Люксембург, Нидерланды, Португалия, Испания, Швеиия и Великобритания.

Источники: Рассчитано по данным Евростата [Eurostat 2012]; расчеты для Ирландии основаны на данных Huтаn Mortality Database [2012b].

Результаты для ЕС-15 показывают согласованную картину. Изначальные значения ИИЗ непрерывно снижаются в зависимости от года рождения когорты, поскольку это был период резкого снижения рождаемости, особенно в Южной Европе. Впоследствии наблюдается устойчивый рост ИИЗ по мере взросления каждой когорты. Когорта 1980 г. при рождении была примерно на $12 \%$ меньше среднего размера "материнской когорты" $(И И 3=0,88)$. Но уже к возрасту 30 лет эта когорта превосходит материнскую на $4 \%$. Когорты, рожденные позже, появились на свет при еще более низком уровне рождаемости и вряд ли сумеют превзойти по численности материнское поколение за оставшуюся жизнь. Тем не менее они очевидно приближаются к заветному уровню замещения поколений. Сходная картина представлена на рисунке 5 для Бельгии, Франции, Германии, 
Италии, Швеции, Швейцарии и Великобритании. В основном кривые стартуют ниже единицы, иногда значительно ниже (например, Швейцария), отражая уровень рождаемости ниже простого воспроизводства. С взрослением когорт, как правило, наблюдается их увеличение, хотя бывают и некоторые спады. Возраста и когорты, в которых отмечается максимальный прирост, также разняться, и можно проследить влияние специфических миграционных событий. К примеру, значительный рост численности всех когорт в Германии в 1990-х годах был вызван масштабным притоком беженцев из бывшей Югославии и возвращением этнических немцев из распавшегося СССР и из Румынии. Несмотря на все различия стран, значительная схожесть отображенных на графиках трендов очевидна. Швейцария, пожалуй, демонстрирует самый поразительный и стабильный тип восполнения нехватки рождений за счет систематической компенсирующей иммиграции на протяжении нескольких десятилетий. Напротив, очень низкая рождаемость в Германии вместе с менее интенсивной иммиграцией ведет к тому, что значение ИИЗ остается ниже единицы для всех наблюдаемых когорт.

Результаты для Испании демонстрируют иную закономерность; соответственно для его отображения на графике использована иная шкале, поскольку рождаемость в Испании долгое время оставалась более высокой и значение ИИЗ в возрасте 0 лет не опускалось ниже единицы вплоть до когорты 1982 г. (на графике отображена когорта 1985 г.). Масштабный приток мигрантов в Испанию в последние два десятилетия (до недавней рецессии) также отчетливо прослеживается в линиях когорт на графике. Иммиграция в Испанию с запасом компенсировала недостаток рождений в когортах. В какой-то мере точное положение испанских кривых можно считать предположительным, поскольку значительная часть иммиграционных потоков в Испанию была изначально не задокументирована и только позже была учтена в ходе серии амнистий. Тем не менее не вызывает сомнений мощность замещающей миграции в Испании. Ни одна другая страна Европы не знала подобного уровня иммиграции. Только за первое десятилетие XX века к 40-миллионному населению Испании добавилось 5,2 млн человек [Sobotka 2009]. При уникальной комбинации сверхнизкой рождаемости и массивной иммиграции Испания представляет собой любопытный пример страны, в которой на протяжении взросления когорт происходит отчетливый «скачок» ИИЗ значительно выше уровня простого замещения поколений, что предполагает существенный рост численности населения.

Следующие два графика на рисунке 5 (для Чехии и Венгрии) показывают еще один вариант. Вплоть до падения социалистического лагеря в 1989 г. международная миграция была здесь незначительной, поэтому линии когорт идут горизонтально с небольшими отклонениями, возможно, указывающими на некоторые отличия оценок численности населения и их корректировок по результатам переписей населения. Но впоследствии, по аналогии со «старыми» членами ЕС, иммиграция начинает и здесь играть значительную роль. В Чехии, начиная с момента вступления в ЕС в 2004 г., отмечается рост показателя ИИЗ. Четкий разлом, произошедший после падения коммунизма, виден и на графике Венгрии, где для молодых когорт также характерен постепенный рост показателя ИИЗ. Этот рост в большой степени обусловлен возвращением этнических венгров из соседних стран, особенно из Румынии. 


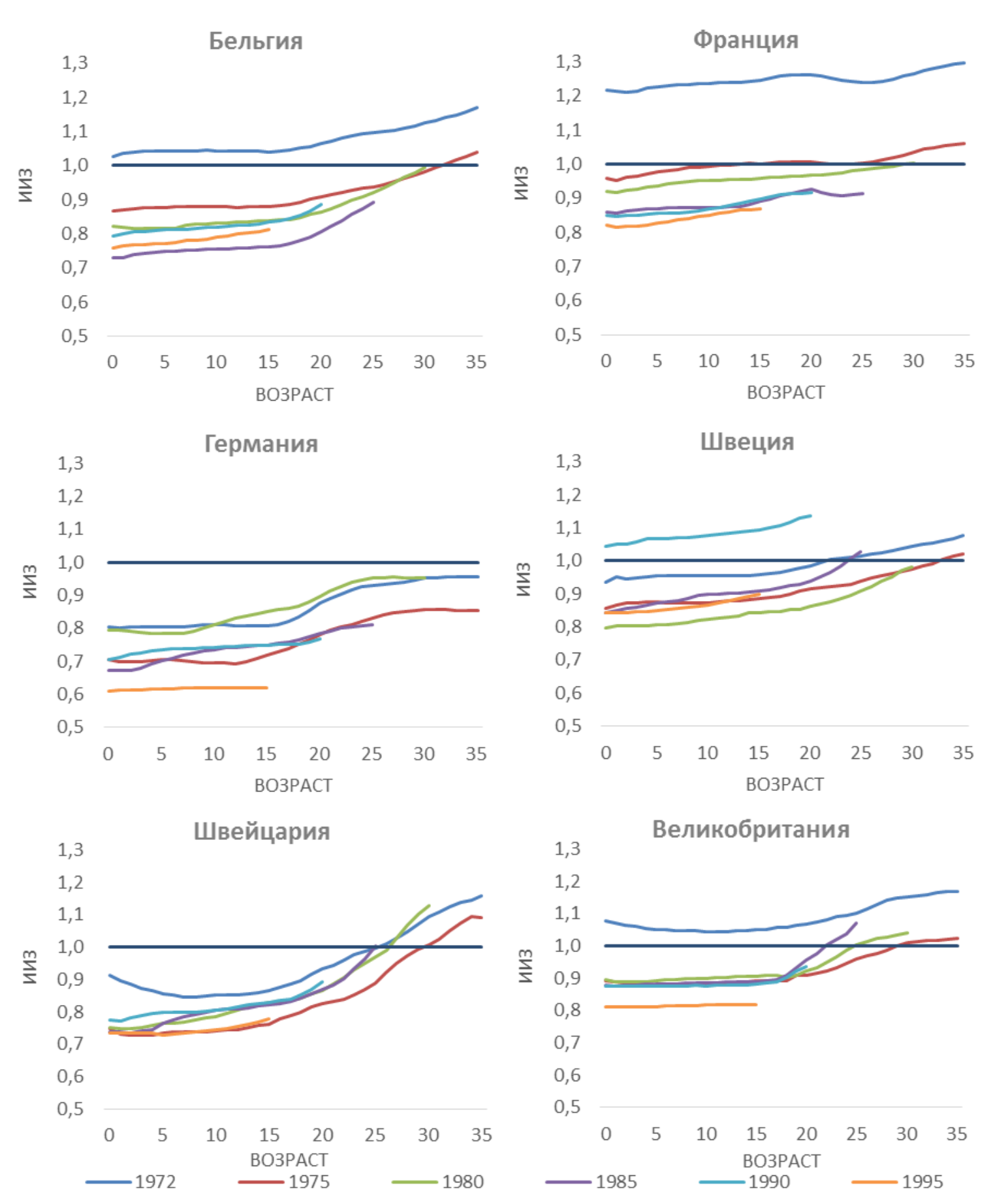

Рисунок 5. Индексы итогового замещения по возрасту для 12 Европейских стран, некоторые когорты 1972-1995 годов рождения

Источник: Рассчитано по данным Евростата [Eurostat 2012]. 

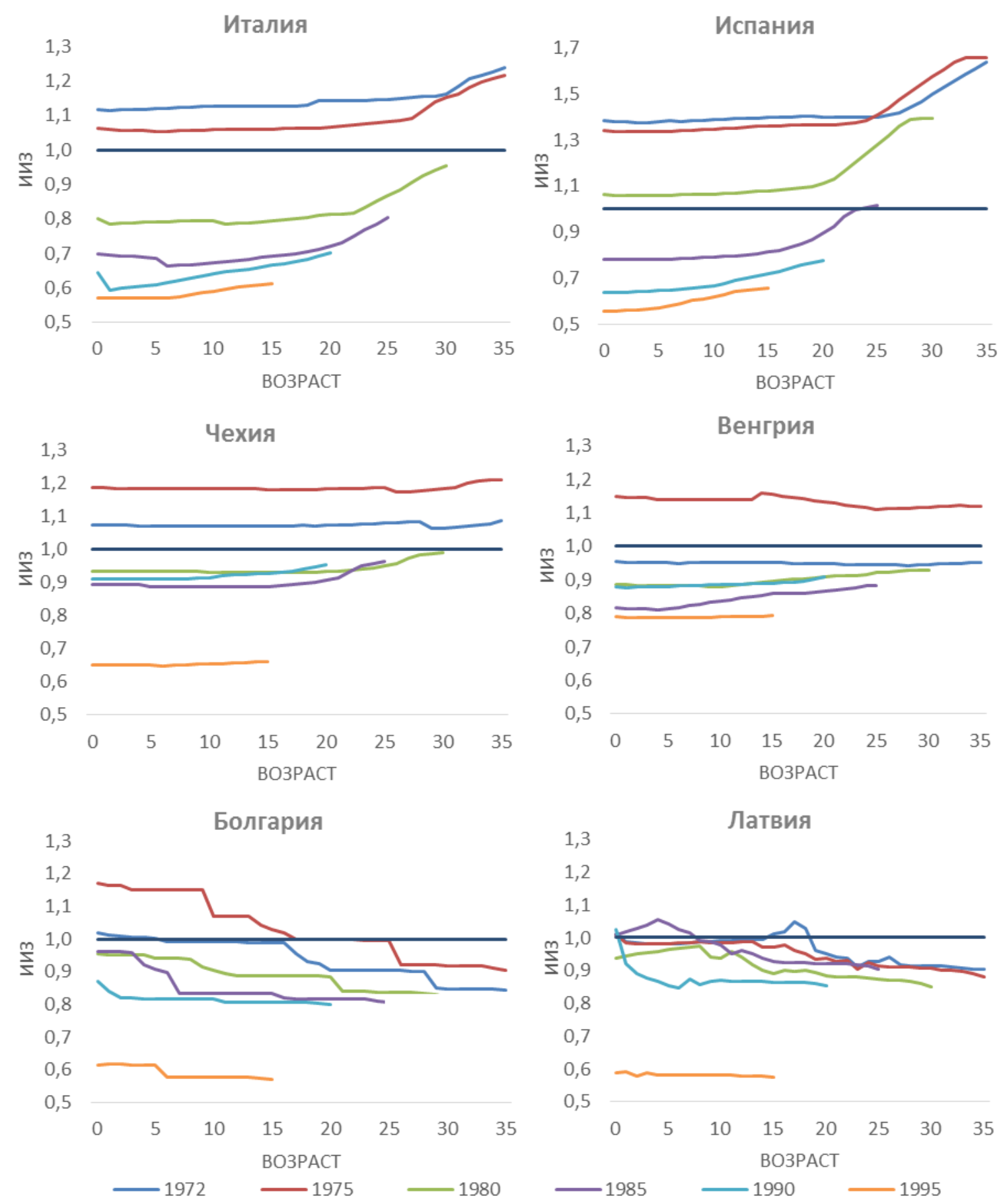

Рисунок 5 (продолжение). Индексы итогового замещения по возрасту для 12 Европейских стран, некоторые когорты 1972-1995 годов рождения

Примечание: Данные для Испании отображены в отличном от других стран масштабе (см. по тексту).

Источник: Рассчитано по даннылм Евростата [Eurostat 2012].

Наконец, последние два графика отражают ситуацию в странах Юго-Восточной и Восточной Европы, испытавших значительную эмиграцию, которая, как правило, плохо документируется. Поэтому официальные данные зачастую показывают странные и нереалистичные скачки и нестыковки. Тем не менее графики для Болгарии и Латвии четко 
рисуют картину быстро сокращающихся населений. Каждая последующая когорта «стартует» со все более низкими показателями ИИЗ (особенно в Болгарии), и затем ее численность постоянно сокращается по мере того, как эмиграция истощает молодое постоянное население этих стран. Наиболее выразительный эффект эмиграции наблюдается у когорты 1975 года рождения в Болгарии, которая при рождении имела ИИЗ значительно выше уровня простого воспроизводства $(1,17)$, но впоследствии сократилась более чем на четверть, почти достигнув значения 0,9 к возрасту 35 лет (2010 г.).

\section{РеГИОНАЛЬНОЕ СРАВНЕНИЕ}

Чтобы более системно оценить замещение населения в различных частях Европы, обратимся к таблице 2. В ней отражен ИИЗ в возрастах 0 и 30 лет для двух женских когорт - 1975 и 1980 г., родившихся в период снижения рождаемости. Данные по странам сгруппированы по более крупным регионам. Снижение рождаемости в конце 1970-х годов отчетливо проявляется в падении или стагнации ИИЗ в возрасте 0 лет между двумя когортами (Германия, где рождаемость резко упала до 1975 г., - исключение). Однако к возрасту 30 ситуация уже не настолько очевидна: Австрия, Бельгия, Германия, Ирландия, Швеция, Швейцария и Великобритания испытали рост ИИЗ(30) между когортами 1975 и 1980 годов рождения. Высокая рождаемость в 1980 г. в комбинации с последующей интенсивной иммиграцией в Ирландии привели к увеличению ИИЗ(30) до 1,75. Почти повсеместно в Европе (за исключением Ирландии и некоторых стран Южной и Восточной Европы) когорта 1980 года рождения стартовала с уровня ниже простого воспроизводства. К возрасту 30 лет, тем не менее, ИИЗ вышел на уровень простого замещения или даже выше и практически везде превысил отметку 0,9 (кроме Дании и некоторых посткоммунистических стран). Поскольку и после 30 лет вполне вероятен прирост численности когорты, нам кажется обоснованным предположить, что в большинстве стран Европы показатель ИИЗ для когорты 1980 года рождения при достижении возраста 40 лет превысит единицу. Лишь в некоторых посткоммунистических странах ИИЗ демонстрировал снижение в данной когорте, хотя в некоторых случаях, включающих Болгарию, Латвию и Румынию, его значение очень резко упало, что, по-видимому, долгое время будет оказывать негативное влияние на возрастную структуру населения. Эти страны оказались перед лицом безрадостной перспективы значительной и длительной депопуляции, особенно, если молодежь малочисленных поколений 1990-х и 2000-х годов продолжит интенсивно эмигрировать.

Практически во всех проанализированных нами странах рост ИИЗ в когорте 1980 года рождения был выше, чем в когорте 1975 г. Абсолютные и относительные приросты ИИЗ между возрастами 0 и 30 лет особенно существенны в Ирландии, Испании и Швейцарии, где абсолютный прирост находился в диапазоне 0,27 - 0,38 для когорты 1980 года рождения. Коротко говоря, даже страны с очень низкой рождаемостью и неттокоэффициентом воспроизводства порядка 0,7 (т.е. с $K C P$ ниже 1,5) могут достичь замещения миграцией уже к возрасту 30 лет. Венгрия и Чехия проделали путь от сокращающегося ИИЗ в когорте 1975 года рождения к росту в когорте 1980 г., что напоминает эволюцию показателя в странах Южной Европы немногим ранее. 


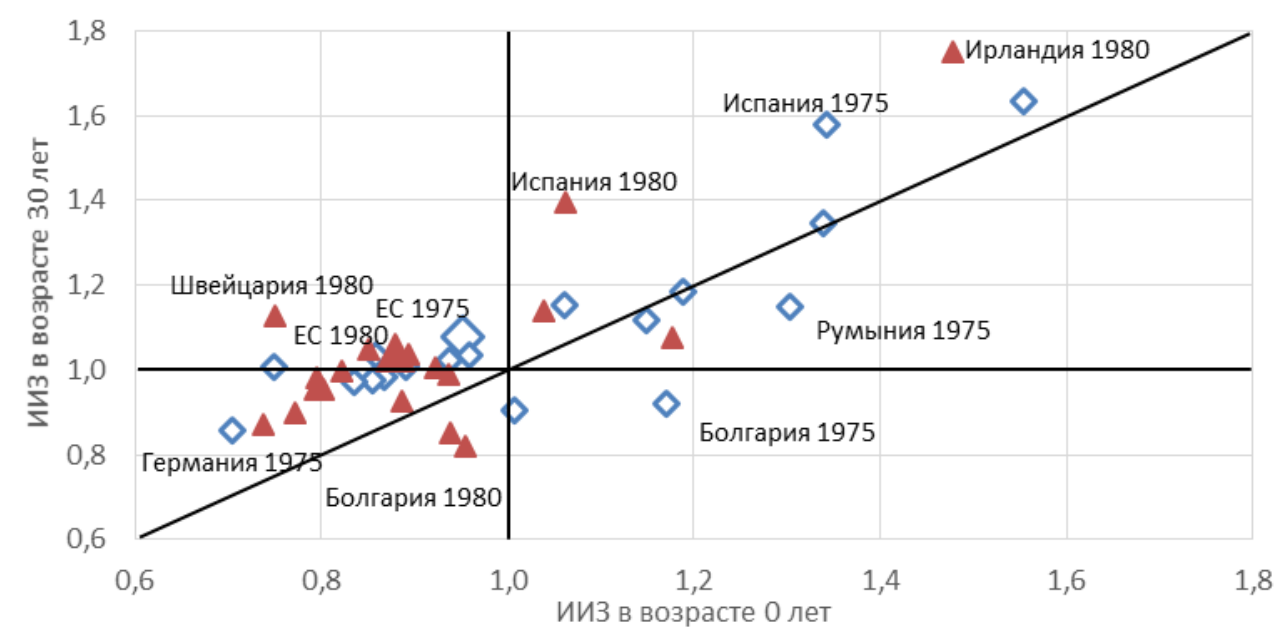

Рисунок 6. Индекс итогового замещения для когорт 1975 (ромбы) и 1980 (треугольники) годов рождения в возрастах 0 и 30 лет в 18 странах Европы, представленных в таблице 2

Примечание: Данные для ЕС-15 отображены более крупными маркерами.

Источники: Рассчитано по данным Евростата [Eurostat 2012]; даннье для Ирландии взяты из Нитап Mortality Database [2012]).

\section{Таблица 2. Индекс итогового замещения для женских когорт 1975 и 1980 годов рождения в возрастах 0 и 30 лет в некоторых странах Европы}

\begin{tabular}{|c|c|c|c|c|c|c|c|c|}
\hline \multirow[t]{2}{*}{ Страна } & \multicolumn{2}{|c|}{$\begin{array}{c}\text { ИИЗ в возрасте } \\
0 \text { лет }\end{array}$} & \multicolumn{2}{|c|}{$\begin{array}{c}\text { ИИЗ в возрасте } \\
30 \text { лет }\end{array}$} & \multicolumn{2}{|c|}{$\begin{array}{c}\text { Абсолютный прирост } \\
\text { ИИЗ в интервале } \\
\text { возрастов } 0-30 \text { лет }\end{array}$} & \multicolumn{2}{|c|}{$\begin{array}{c}\text { Относительное } \\
\text { изменение (индекс): } \\
\text { ИИЗ (30) / } \\
\text { ИИЗ (0) }\end{array}$} \\
\hline & 1975 & 1980 & 1975 & 1980 & 1975 & 1980 & 1975 & 1980 \\
\hline EC-15 & 0,95 & 0,88 & 1,08 & 1,04 & 0,13 & 16 & 1,13 & 1,18 \\
\hline \multicolumn{9}{|l|}{ Западная Европа } \\
\hline Бельгия & 0,87 & 0,82 & 0,98 & 1 & 0,11 & 17 & 1,13 & 1,21 \\
\hline Франция & 0,96 & 0,92 & 1,04 & 1,01 & 0,08 & 08 & 1,08 & 1,09 \\
\hline Ирландия & 1,55 & 1,48 & 1,63 & 1,75 & 0,08 & 27 & 1,05 & 1,18 \\
\hline Нидерланды & 0,83 & 0,77 & 0,97 & 0,9 & 0,14 & 13 & 1,17 & 1,16 \\
\hline Великобритания & 0,89 & 0,89 & 1,01 & 1,04 & 0,12 & 14 & 1,13 & 1,16 \\
\hline \multicolumn{9}{|l|}{ Северные страны } \\
\hline Дания & 0,94 & 0,74 & 1,02 & 0,87 & 0,09 & 13 & 1,09 & 1,18 \\
\hline Швеция & 0,85 & 0,8 & 0,97 & 0,98 & 0,12 & 19 & 1,14 & 1,23 \\
\hline \multicolumn{9}{|l|}{ Германоязычные } \\
\hline Австрия & 0,86 & 0,85 & 1,03 & 1,05 & 0,17 & ),2 & 1,2 & 1,23 \\
\hline Германия & 0,71 & 0,79 & 0,86 & 0,95 & 0,15 & 16 & 1,21 & 1,2 \\
\hline Швейцария & 0,75 & 0,75 & 1,01 & 1,13 & 0,26 & 38 & 1,34 & 1,5 \\
\hline \multicolumn{9}{|l|}{ Южная Европа } \\
\hline Италия & 1,06 & 0,8 & 1,15 & 0,95 & 0,09 & 15 & 1,08 & 1,19 \\
\hline Португалия & 1,34 & 1,04 & 1,35 & 1,14 & 0,01 & ),1 & 1,01 & 1,1 \\
\hline Испания & 1,34 & 1,06 & 1,58 & 1,4 & 0,24 & 33 & 1,18 & 1,31 \\
\hline \multicolumn{9}{|c|}{ Центральная и Восточная Европа } \\
\hline Венгрия & 1,15 & 0,89 & 1,12 & 0,93 & $-0,03$ & 04 & 0,97 & 1,05 \\
\hline Чехия & 1,19 & 0,94 & 1,19 & 0,99 & 0 & 05 & 1 & 1,06 \\
\hline Болгария & 1,17 & 0,95 & 0,92 & 0,82 & $-0,25$ & 13 & 0,79 & 0,86 \\
\hline Латвия & 1,01 & 0,94 & 0,91 & 0,85 & $-0,1$ & 09 & 0,9 & 0,91 \\
\hline Румыния & 1,3 & 1,18 & 1,15 & 1,07 & $-0,15$ & ),1 & 0,88 & 0,91 \\
\hline
\end{tabular}

Источники: Рассчитано по данным Евростата [Eurostat 2012]; данные для Ирландии взяты из [Human Mortality Database 2012b]. 


\section{ВЫВОДЫ И ПРИКЛАДНОЕ ЗНАЧЕНИЕ}

Шесть десятилетий назад Хирениус [Hyrenius 1951] показал принципиальное различие между биологическим воспроизводством и социальным замещением. С тех пор многочисленные исследования искали ответ на вопрос, может ли миграция частично или полностью возместить недостаток рождений и дисбаланс населения, особенно в богатых странах и регионах. Многие из этих исследований сосредоточились на поиске уровней и моделей миграции, необходимых для достижения стабильного населения при наблюдаемых и гипотетических уровнях рождаемости и смертности. На фоне относительно высокой миграционной активности последних десятилетий (особенно до 2009 г.) в большинстве развитых стран дебаты о роли замещающей миграции усилились. Исследования долгосрочных эффектов миграции долгое время были затруднены из-за несовершенства данных о миграционных потоках и из-за отсутствия общепринятых стандартных измерителей и показателей.

Наше исследование фокусирует внимание на трех основных моментах. Во-первых, мы подчеркиваем различие между влиянием миграции на замещеене рождений (т.е. вкладом мигрантов в рост наблюдаемого или гипотетического числа рождений) и на замещение населения (т.е. на восполнение мигрантами провалов в населения, обусловленных рождаемостью ниже уровня простого воспроизводства). Во-вторых, мы предлагаем простой показатель когортного замещения населения. В-третьих, наш новый показатель, который был разработан параллельно с аналогичным индексом Далла Зуаны [Dalla Zuanna 2008], проясняет природу изменения населения во многих частях Европы и убедительно показывает нереалистичность некоторых недавних прогнозов неизбежного снижения численности ее населения. Очевидно, что, хотя идея замещающей миграции, выдвинутая ООН в 2000 г., была раскритикована, именно такая миграция в действительности имеет место в большей части Европы.

Демографические процессы по своей природе неустойчивы, поэтому теория стабильного населения никогда не находит эмпирического подтверждения в длительной перспективе. Учитывая это, удивительно наблюдать, что во многих странах Европы женские когорты, рожденные в период суженного воспроизводства, достигают уровня простого замещения к вступлению в наиболее активный детородный возраст. Применяя иной подход, Алхо показал, что низкая рождаемость в Европе «ассоциируется с высоким миграционным приростом и vice versa» [Alho 2008: 644], подразумевая, что миграция сгладила различия в истинном коэффициенте естественного прироста населения в Европе. Похожим образом Биллари и Далла Зуана [Billari, Dalla Zuanna 2011: рисунок 2] показали, что интенсивность миграции сильно и с обратной зависимостью коррелирует с динамикой рождений. Однако подобные наблюдения необходимо рассматривать в более широком контексте. Часто влияние миграции идет намного дальше небольшой «дозаправки» численности населения, и некоторые страны явно «перестарались» в этом отношении и испытывают сейчас значительный рост населения за счет иммиграции (например, Ирландия, Испания и Швейцария). Напротив, некоторые страны Восточной и ЮгоВосточной Европы, часто исключаемые из сравнительного анализа стран Европы, начиная с 1990-х годов испытали синергетический негативный эффект низкой рождаемости и 
масштабной эмиграции и оказались перед перспективой значительного сокращения населения.

Пример Испании или Швейцарии показывает, что даже очень низкий уровень рождаемости не препятствует простому или даже расширенному замещению поколений благодаря миграции. Наиболее богатые страны из присоединившихся к Европейскому Союзу в 2004 г. (например, Чехия и Словения) следуют этому же сценарию. Разумеется, есть множество региональных особенностей и исключений из общего тренда. Некоторые богатые страны, например Германия и Нидерланды, испытывали в прошлом непродолжительные периоды потери населения за счет эмиграции, а недавняя экономическая рецессия спровоцировала отток населения из некоторых других стран. Наименее зажиточные страны ЕС, в особенности страны Прибалтики, Болгария и Румыния, а также почти все остальные восточноевропейские страны за пределами ЕС и по сей день испытывают масштабную эмиграцию. Тем не менее можно провести историческую параллель между современной эмиграцией из таких стран, как Польша или Румыния, с массовым оттоком населения из Италии, Португалии и Испании в 1950-70 годах. Эти три страны в недавнем прошлом стали крупными реципиентами населения. Их пример указывает на возможный путь демографического развития для стран, примкнувших к ЕС в 2004 и 2007 г. Вероятно, и их в ближайшем будущем ожидает масштабная замещающая иммиграция.

Сама по себе замещающая миграция не может быть лекарством от старения населения в Европе. Она, скорее, представляет собой привлекательную возможность, которая должна быть грамотно использована вместе с мерами, направленными на социально-экономическую устойчивость (включая и помощь в интеграции мигрантов), увеличение женского присутствия на рынке труда, откладывание выхода на пенсию и увеличение доступности высшего образования как для местного, так и для прибывающего населения. Некоторые настороженно настроенные к мигрантам правительства стараются стимулировать рост рождаемости, сокращая при этом иммиграцию. Однако предыдущий опыт европейских стран ясно показывает, что ни пронаталистские, ни антимигрантские политические меры, как правило, не достигают желаемых целей и могут даже вести к противоположным результатам [Castles 2004; Gauthier 2007].

Измеритель, предложенный в данной работе (ИИЗ), позволяет проводить межстрановые сравнения во времени даже при наличии исключительно базовых статистических данных. Отражая относительные изменения численности когорты, ИИЗ демонстрирует значительно большую устойчивость, чем показатели, опирающиеся исключительно на данные для календарных периодов. Такие показатели, рассчитанные по данным лишь одного года, например индексы, предложенные Эдиевым и соавторами [Ediev et al. 2007, 2012] и Престоном и Вангом [Preston, Wang 2007], подвержены влиянию как ежегодных колебаний миграции, так и неполноты миграционной статистики. В то же время на более продолжительном временном отрезке неточности миграционного учета и оценок численности населения сглаживаются, что делает ИИЗ подходящим показателем для изучения замещения населения. Скромные запросы к данным делают его идеальным для анализа как современных, так и исторических населений. Также удобно изучать динамику населения на внутристрановом уровне, где внутренняя миграция зачастую играет большую 
роль, нежели международная (см. [Wilson, Williamson 2011] - данные по Великобритании; [del Rey Poveda, Cebran-Villar 2010] - некоторые регионы Испании; [Billari, Dalla Zuanna 2011; Dalla Zuanna 2008] - регионы Италии). Показатель может быть использован для менее развитых стран, где ограничения в данных более существенные. Кроме того, ИИЗ может быть рассчитан для разных возрастных групп, гибко отвечая на потребности разных аналитиков. В то время как мы выбрали для основного анализа возраст 30 лет как серединный рубеж репродуктивного пути, ИИЗ может быть использован для отслеживания изменений относительного размера когорт на протяжении рабочих возрастов, когда мигранты вливаются в состав рабочей силы, или для анализа изменений в относительном размере когорт перед выходом на пенсию.

В Приложении, в котором мы сравниваем ИИЗ в возрастах 0 и 30 лет с общепринятыми нетто- и брутто-коэффициентами воспроизводства для Швеции по данным за 1850-2010 гг., показано, что ИИЗ можно использовать в качестве довольно точной оценки этих традиционных показателей замещения, когда более детальные данные рождаемости и смертности недоступны. Несмотря на свою простоту, ИИЗ обычно работает не хуже более сложных показателей когортного замещения. При нормальных условиях он относительно нечувствителен к способу определения материнской когорты. При отсутствии значительных внезапных перепадов в численности материнской когорты возможная ошибка в результате неточного определения материнского поколения будет значительно меньше ошибок и неточностей, связанных с дефинициями, используемыми в официальной статистике многих стран. ИИЗ не призван, конечно, заменить какой-либо из существующих более сложных показателей динамики населения, но мы полагаем, что он может быть полезен в качестве простого инструмента для изучения совместного влияния рождаемости и миграции на межпоколенное замещение.

\section{ПРИЛОЖЕНИЕ}

Сравнение итогового индекса замещения, нетто- и бруттокоэффициентов воспроизводства в Швеции в 1950-2010 22.

Ключевое допущение при расчете ИИЗ заключается в том, что возрастной профиль рождаемости учитывается в очень упрощенном виде путем указания верхней и нижней границ основных детородных возрастов. Уместность подобного допущения можно проверить путем сравнения традиционного брутто-коэффициента воспроизводства с ИИЗ, рассчитанного при рождении (число рождений в данном году, деленное на средний размер материнской когорты в том же году).

На рисунке П1 представлены $R$ и ИИЗ (при рождении), определенные тремя способами для Швеции за период с 1852 по 2005 г. Ежегодные значения усреднены методом скользящего среднего по пятилетним интервалам для избежания случайных флуктуаций. Ясно, что с течением времени меняется наиболее подходящее определение возрастного интервала для материнских когорт (20-35, 20-40 и 20-45 лет). Однако в любой момент времени наиболее подходящий ИИЗ (при рождении) дает значения, очень близкие к значениям $R$. За весь 153-летний период наблюдения наиболее подходящий ИИЗ (при 
рождении) отклоняется от $R$ не более чем на $3 \%$. В таблице П1 приведены наиболее подходящие возрастные интервалы для различных периодов. С 1852 по 1911 г. самое широкое определение материнской когорты (20-45 лет) дает наилучший результат, в следующие 30 лет (1912-1942 гг.) предпочтительнее возрастной интервал 20-40 лет. С 1940х годов начался период, для которого невозможно указать однозначно более подходящий возрастной интервал матерей, однако с 1967 по 1998 г. (период, представляющий основной интерес для данной статьи) наилучшим образом подходит возрастной интервал 20-35 лет. Именно поэтому мы используем его в наших расчетах, связанных с замещающей миграцией.

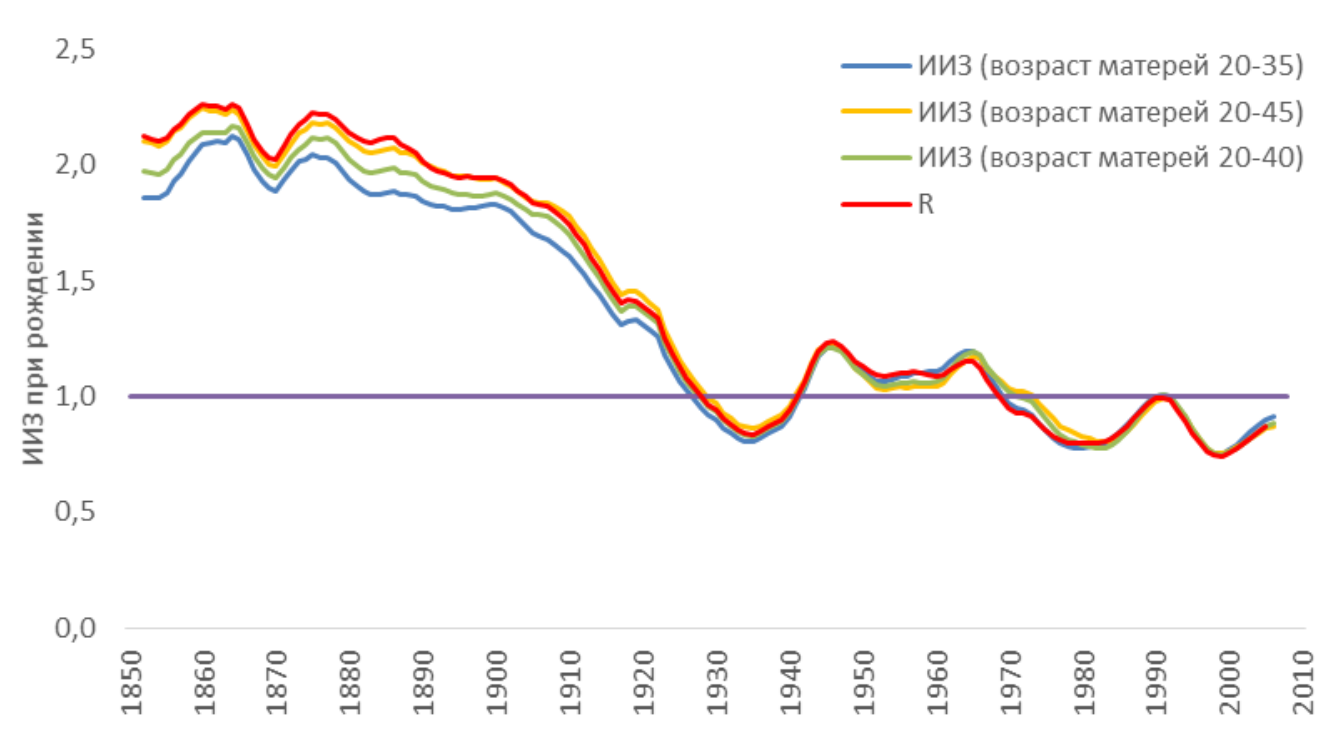

Рисунок П1. Брутто-коэффициент воспроизводства и три варианта индекса итогового замещения при рождении с различным определением границ основных репродуктивных возрастов: 20-35, 20-40, 20-45 лет; Швеция, 1892-2005

\footnotetext{
Примечание: Представлены усредненные данные (5-летнее скользящее среднее по однолетним даннылм).
}

Источники: [Human Fertility Database 2012], [Festy 1979].

Характер изменения наиболее подходящего возрастного интервала материнской когорты очень логичен, если сопоставить его с тем, что мы знаем об изменении возрастного профиля рождаемости. На протяжении второй половины XIX - начала XX веков рождаемость была относительно высокой во всех репродуктивных возрастах. Поэтому возрастной интервал 20-45 лет подходит больше всего. С началом спада рождаемости ее наиболее интенсивное снижение наблюдалось в старших репродуктивных возрастах. И интервал 20-40 лет стал давать лучшие результаты на этом временном отрезке. С дальнейшим снижением рождаемости максимальная интенсивность процесса еще больше сконцентрировалась в молодых возрастах, и интервал 20-35 лет стал предпочтительным. Наконец, из-за увеличивающегося откладывания рождений после бэби-бума 1960-х годов более широкий возрастной интервал вновь стал давать наилучшие результаты. Разумеется, конкретные исторические периоды, для которых предпочтителен тот или иной возрастной интервал материнской когорты, варьируются от страны к стране. Но общая модель 
изменений схожа во всех странах Западной Европы, и для наиболее интересующего нас сейчас периода самым подходящим оказался возрастной интервал 20-35 лет.

Таблица П1. Наиболее подходящее (best-fitting) определение границ интервала основных репродуктивных возрастов материнского поколения для расчета индекса итогового замещения при рождении, дающее максимальное приближение к бруттокоэффициенту воспроизводства, и среднее отклонение от него, Швеция, 1892-2005

\begin{tabular}{l|c|c}
\hline Период & Наиболее подходящий возрастной интервал & Среднее отклонение, \% \\
\hline $1852-1911$ & $20-45$ & 1,10 \\
$1915-1942$ & $20-40$ & 1,42 \\
$1943-1947$ & $20-45$ & 0,96 \\
$1948-1962$ & $20-35$ & 1,81 \\
$1962-1966$ & $20-45$ & 2,80 \\
$1967-1988$ & $20-35$ & 1,43 \\
$1999-2005$ & $20-40$ & 0,52 \\
\hline
\end{tabular}

Примечание: Представлены усредненные данные (5-летнее скользящее среднее по однолетним даннымм).

Источники: [Human Fertility Database 2012], [Festy 1979].

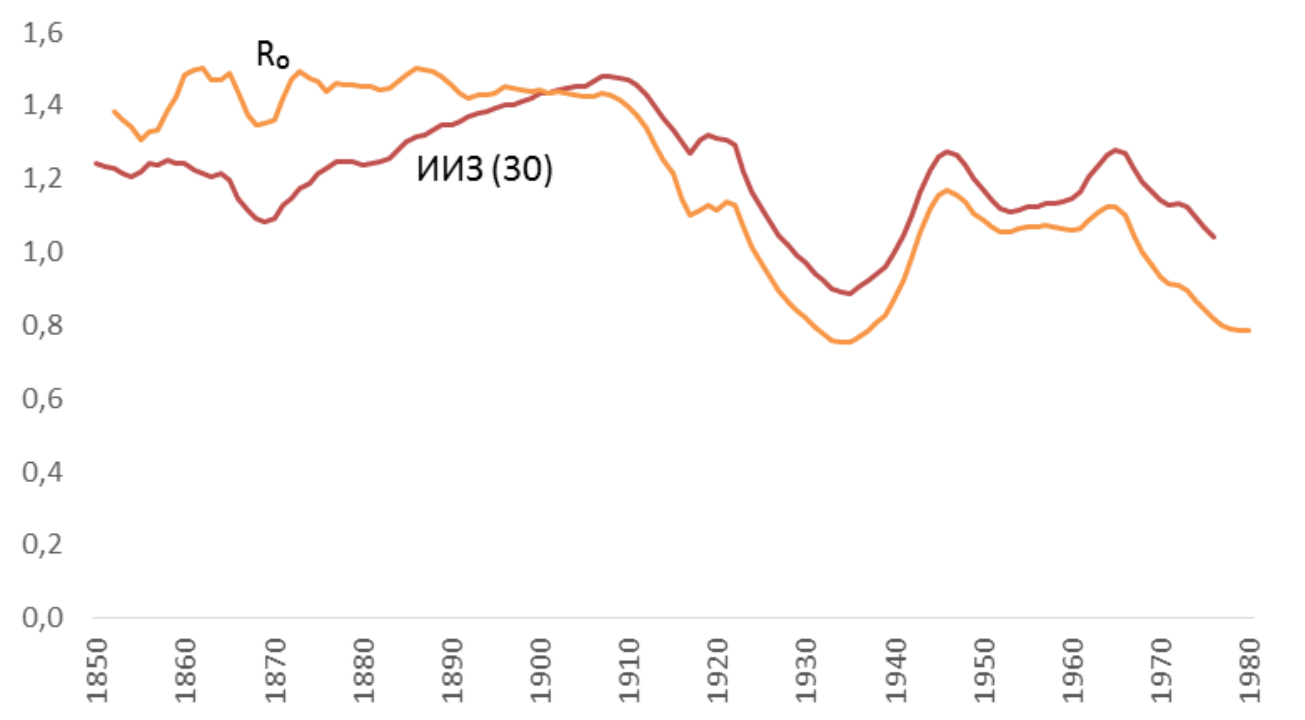

Рисунок П2. Индекс итогового замещения в возрасте 30 лет и нетто-коэффициент воспроизводства, Швеция, 1852-1976

Примечание: Обе линии отражают скользящие 5-летние средние из ежегодных оценок показателей. При расчете ИИЗ использовался возрастной интервал 20-45 лет для материнского поколения.

Источники: [Festy 1979; Human Fertility Database 2012; Human Mortality Database 2012a].

Дальнейшее сравнение, которое помогает нам оценить потенциальную ценность ИИЗ, - с нетто-коэффициентом воспроизводства. Рисунок П2 отражает ежегодный (для календарного периода) $N R R$ для Швеции за 1852-1976 гг. в сравнении с ИИЗ в возрасте 30 лет для когорт, рожденных в 1852-1976 гг. Возраст 30 лет выбран в качестве приблизительного значения возраста чистого замещения поколения. Вновь обе линии сглажены по методу скользящего среднего (5-летние интервалы). Можно ожидать, что два показателя будут немного отличаться, поскольку на протяжении анализируемого периода 
шло снижение смертности и с каждым годом когорта испытывала ее меньшее влияние, нежели в год ее рождения. Поэтому при прочих равных условиях линия ИИЗ(30) может быть немного выше, чем $G R R$, из-за снижающейся смертности. Однако основной фактор расхождения этих показателей - все же миграция. C 1860 г. до Первой мировой войны примерно одна треть всего естественного прироста населения Швеции терялась из-за эмиграции (в основном в США). Вот почему на графике линия ИИЗ(30) проходит существенно ниже линии GRR на протяжении многих десятилетий. Однако начиная с межвоенного периода Швеция стала миграционным реципиентом, и, как отчетливо видно на рисунке П2, линии двух показателей пересекаются - ИИ3(30) становится больше GRR. Расхождение линий в правой части графика (наиболее интересующее нас в данной статье явление) отражает увеличивающееся значение замещающей миграции как фактора динамики населения. В целом график показывает, что ИИЗ может быть ценным дополнением к базовому методологическому арсеналу демографа: $G R R$ отражает уровень рождаемости, $N R R$ сокращает его, отражая вклад смертности, а ИИЗ привносит результаты воздействия миграции.

\section{ПРИМЕЧАНИЯ}

Исследование Уилсона, Уильямсона и Бойля, результаты которого представлены в данной статье, поддержаны Центром изучения изменений населения (ESRC Centre for Population Change). Работа Соботки частично финансировалась Европейским исследовательским советом (European Research Council) в рамках Седьмой рамочной программы Европейского Союза (European Union's Seventh Framework Programme, FP7/2007-2013) / ERC, номер гранта 284238. Ранние версии статьи были представлены в Вене в сентябре 2010 г. в рамках Европейской конференции народонаселения (European Population Conference), а также опубликованы в качестве препринта Центра изучения изменений населения (ESRC Centre for Population Change) [Wilson et al. 2010]. Мы получили ценные комментарии от Марии Ни Брольхан (Maire Ni Bhrolchain), Жанпьеро Далла Зуанны (Gianpiero Dalla Zuanna), Джошуа Гольдштейна (Joshua Goldstein), Элспет Грэхэм (Elspeth Graham) и участников Европейской демографической конференции-2010 (European Population Conference 2010). Мы также благодарим Криштофа Земана (Kryštof Zeman) за предоставление расчетов некоторых показателей для Швеции, использованных на рисунке 2, и Далхата Эдиева (Dalkhat Ediev) за предоставление еще неопубликованного текста статьи о воспроизводстве населения [Ediev et al. 2012].

\section{ЛИТЕРАТУРА}

Alho J. M. (2008). Migration, Fertility, and Aging in Stable Populations // Demography. 45(3): $641-650$.

Avdeev A., T. Eremenko, P. Festy, J. Gaymu, N. L. Bouteillec, S. Springer (2011). Populations and Demographic Trends of European Countries, 1980-2010 // Population-E. 66(1): 9-130. 
Beaujot R. (2003). Effect of Immigration on the Canadian Population: Replacement Migration? // Discussion Papers Series. 03-03. Population Studies Centre. University of Western Ontario. London. URL: http://www.ssc.uwo.ca/sociology/popstudies/dp/dp03-03.pdf.

Bijak J., D. Kupiszewska, M. Kupiszewski, K. Saczuk, A. Kicinger (2007). Population and labour force projections for 27 European countries, 2002-052: impact of international migration on population ageing // European Journal of Population. 23(1): 1-31.

Billari F.C., G. Dalla Zuanna (2011). Is replacement migration actually taking place in low fertility countries? // Genus. 67(3): 105-123.

Calot G., J.P. Sardon (2001). Fécondité, reproduction et remplacement // Population. 56(3): 371396.

Castles S. (2004). Why migration policies fail // Ethnic and Racial Studies. 27(2): 205-227.

Coale A. J. (1986). Demographic Effects of Below-Replacement Fertility and Their Social Implications // Population and Development Review. 12: 203-216.

Coleman D. (2001). Replacement migration, or why everyone is going to have to live in Korea: A fable for our times from the United Nations // Philosophical Transactions of the Royal Society B. 357: 583-598.

Coleman D. (2006). Immigration and Ethnic Change in Low-Fertility Countries: A Third Demographic Transition // Population and Development Review. 32(3): 401-446.

Coleman D. (2009). Introduction: migration and its consequences in 21st century Europe // Vienna Yearbook of Population Research. 1-18.

Daguet F. (2002). Le remplacement des generations // Un Siècle de Fécondité Française: Caractéristiques et Evolution de la Fécondité de 1901 á 1999. Paris: INSEE: 235-252.

Dalla Zuanna G. (2006). Population replacement, social mobility and development in Italy in the twentieth century // Journal of Modern Italian Studies. 11(2): 188-208.

Dalla Zuanna G. (2008). La misura RM del rimpiazzo delle generazioni // Popolazione e Storia. 2: $61-72$.

del Rey Poveda A., M. Cebrán-Villar (2010). Population replacement and migration in two Spanish regions during the Twentieth century // Population-E. 65(3): 481-497.

Demeny P. (2003). Population Policy Dilemmas in Europe at the Dawn of the Twenty-First Century // Population and Development Review. 29(1): 1-28.

De Santis G. (2011). Can immigration solve the aging problem in Italy? Not really.... // Genus. 57(3): 37-64.

Ediev D., D. Coleman, S. Scherbov (2007). Migration as a factor of population reproduction // European Demographic Research Papers. 1. Vienna Inst. of Demography. URL: http://www.oeaw.ac.at/vid/download/edrp_1_07.pdf.

Ediev D., S. Scherbov, D. Coleman (2012). New measures of population reproduction for an era of high migration. Unpublished manuscript under review.

Espenshade T.J., L.F. Bouvier, W.B. Arthur (1982). Immigration and the Stable Population Model // Demography. 19(1): 125-133.

Espenshade T.J. (1986). Population Dynamics with Immigration and Low Fertility // Population and Development Review. 12: 248-261.

Espenshade T.J. (2001). "Replacement Migration" from the Perspective of Equilibrium Stationary Populations // Population and Environment. 22(4): 383-389. 
European Commission (2005). Confronting demographic change: a new solidarity between the generations. Green Paper. Brussels: Commission of the European Communities.

Eurostat (2005). EU25 population rises until 2025, then falls // Eurostat news release. 48.

Eurostat (2006). Long-term population projections at national level // Eurostat news release. 3. Luxembourg: European Communities.

Eurostat (2008). Ageing characterises the demographic perspectives of the European societies // Statistics in Focus, Population and Social Conditions. 72/ Luxembourg: European Communities.

Eurostat (2011a). EU 27 population is expected to peak by around 2040 // Eurostat news release. 80.

Eurostat (2011b). Migrants in Europe, 2011 edition. A Statistical Portrait of the First and Second Generation / Eurostat Statistical Books. Luxembourg: Publications Office of the European Union

Eurostat (2012). Population on 1 January by age and sex. URL: http://epp.eurostat.ec.europa.eu/portal/page/portal/statistics/search_database (дата обращения: 03.05. 2012).

Festy P. (1979). La fécondité des pays occidentaux 1870-1970. Présentation d'un cahier de l'INED // Cahier de l'INED. 85. Paris: Presses Universitaires de France.

Gauthier A. (2007). The impact of family policies on fertility in industrialized countries: a review of the literature // Population Research and Policy Review. 26: 232-346.

Gesano G., S. Strozza (2011). Foreign migrations and population aging in Italy // Genus. 57(3): 83-104.

Human Fertility Database (2012). Data on fertility rates in Sweden. URL: http://www.humanfertility.org. (дата обращения: 03.05. 2012).

Human Mortality Database (2012a). Data on female population and mortality tables by age in Sweden. URL: http://www.mortality.org/. (дата обращения: 03.05. 2012).

Human Mortality Database (2012b). Data on female population in Ireland. URL: http://www.mortality.org. (дата обращения: 03.05. 2012).

Hyrenius H. (1951). Reproduction and Replacement: A methodological study of Swedish population changes during 200 years // Population Studies. 4(4): 421-431.

Keely C. (2001). Replacement Migration: the wave of the future? // International Migration. 39(6): 103-110.

Kuczynski R.R. (1928). The balance of births and deaths. Vol. 1. Western and Northern Europe. New York: The MacMillan Company. The Brookings Institution.

Lesthaeghe R. (2000). Europe's demographic issues: Fertility, household formation and replacement migration // Population Studies in Britain and in the Netherlands, Utrecht.

Lutz W., S. Scherbov (2003). Future demographic change in Europe: the contribution of migration // Interim Report № IR-03-66. Laxenburg, Austria: International Institute for Applied Systems Analysis. URL: http://www.iiasa.ac.at/Admin/PUB/Documents/ IR-03066.pdf.

Mcdonald P. (2002). Sustaining Fertility through Public Policy: The Range of Options // Population-E. 57(3): 417-446. 
Office for National Statistics (2010). URL: http://www.statistics.gov.uk/statbase/Product. asp?vlnk=15106 (дата обращения: декабрь 2009 - август 2010).

Oláh L.S., E.M. Bernhardt (2008). Sweden: Combining childbearing and gender equality // Demographic Research. Vol.19. Article 28. URL: http://www.demographicresearch.org/volumes/vol19/28/19-28.pdf.

Ortega J.A., L.A. del Rey Poveda (2007). Birth replacement ratios in Europe: A new look at period replacement / Annual Meeting of the Population Association of America, New York.

Preston S.H., H. Wang (2007). Intrinsic Growth Rates and Net Reproduction Rates in the Presence of Migration // Population and Development Review. 33(4): 657-666.

Ryder N.B. (1997). Migration and Population Replacement // Canadian Studies in Population. 24(1): $1-26$.

Saczuk K. (2003). A Development and Critique of the Concept of Replacement Migration // CEFMR Working Paper. 4. Central European Forum for Migration Research. Warsaw. URL: http://www.cefmr.pan.pl/docs/cefmr_wp_2003_04.pdf.

Smallwood S., J. Chamberlain (2005). Replacement fertility, what has it been and what does it mean? // Population Trends. 119: 16-27.

Sobotka T. (2008a). Does persistent low fertility threaten the future of European populations? / P. Deboosere, J. Surkyn, J. van Bavel, eds. Demographic Challenges for the 21st Century: A State of the Art in Demography. Brussels: VUB Press: 27-89.

Sobotka T. (2008b). The rising importance of migrants for childbearing in Europe // Demographic Research. Special Collection 7. Vol. 19 (Article 9): 225-248.

Sobotka T. (2009). Migration continent Europe. Vienna Yearbook of Population Research, 2009: $217-233$.

Tarmann A. (2000). The flap over replacement migration. URL: http://www.prb.org/Articles/2000/TheFlapOverReplacementMigration.aspx (дата обращения: 04. 2012).

Teitelbaum M.S., J.M. Winter (1985). The Fear of Population Decline. Orlando: Academic Press.

Tietelbaum M.S. (2004). Western experiences with international migration in the context of population decline // Japanese Journal of Population. 2(1): 29-40.

United Nations (2000). Replacement Migration: Is it a Solution to Declining and Ageing Populations? New York: Population Division.

Vatican (2006). Address of His Holiness Benedict XVI to the Roman Curia offering them his Christmas greetings. URL:

http://www.vatican.va/holy_father/benedict_xvi/speeches/2006/december/documents/hf_ben _xvi_spe_20061222_curia-romana_en.html.

VID (2012). European Demographic Data Sheet 2012. Vienna Institute of Demography and IIASA / Wittgenstein Centre for Demography and Global Human Capital. URL: http://www.oeaw. ac.at/vid/datasheet/index.html.

Vos A.E. (2009). Falling fertility rates: new challenges to the European welfare state // SocioEconomic Review. 7(3): 485-503.

Wilson C., T. Sobotka, L. Williamson., P. Boyle (2010). A simple method for estimating intergenerational replacement based on fertility and migration - European examples // ESRC 
Centre for Population Change. Working Paper. 10. URL: http://www.cpc. ac.uk/publications/.

Wilson C., L. Williamson (2011). Intergenerational replacement and migration in the countries and regions of the United Kingdom, 1971-2009 // Population Trends. 145(Autumn): 1-16. 


\title{
MIGRATION AND INTERGENERATIONAL REPLACEMENT IN EUROPE *
}

\section{CHRIS WILSON, TOMÁŠ SOBOTKA, LEE WILLIAMSON, PAUL BOYLE}

Chris Wilson. School of Geography and Geosciences, University of St ANDREws, Fife, Scotland

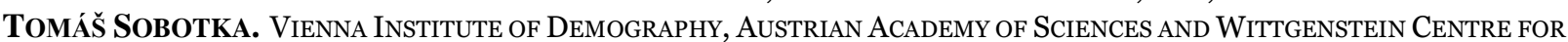
DEMOGRAPHY AND Global Human CAPITAL, VienNa

E-MAIL: tomas.sobotka@oeaw.ac.at

LEE Williamson. School of Geography ANd Geosciences, University of St ANDREWs, Fife, Scotland

Paul Boyle. School of Geography and Geosciences, University of St Andrews, Fife, Scotland

\begin{abstract}
There are long-standing concerns over low fertility levels in Europe and an increasingly important debate on the extent to which migration can compensate for below-replacement fertility. To inform this debate, wide arrays of indicators have been developed to assess the joint influence of fertility, mortality, and migration on birth replacement and intergenerational replacement. These indicators are based on various models and assumptions and some are particularly data demanding. In this article we propose a simple method to assess how far migration alters the extent of replacement for a birth cohort as it ages. We term the measure the overall replacement ratio (ORR). It is calculated by taking the size of a female birth cohort at selected ages divided by the average size of the cohorts of mothers in the year of birth. We present estimates of the ORR for a range of European countries representing different replacement regimes. We demonstrate that for many countries net migration has become a key factor in their population trends during the last few decades.
\end{abstract}

Key words: intergenerational replacement, population replacement, birth replacement, replacement migration, index of replacement.

\footnotetext{
* Reprinted With the Permission of the Population Council from: Wilson C., T. Sobotka, L. Williamson, P. BOYLE (2013). MigRATION AND INTERGENERATIONAL REPLACEMENT IN EUROPE // POPULATION AND DEVELOPMENT REVIEW. 39(1): 131-157.
}

TRANSLATED BY ILYA KASHNITSKY.

\section{REFERENCES}

Alho J. M. (2008). Migration, Fertility, and Aging in Stable Populations // Demography. 45(3): $641-650$.

Avdeev A., T. Eremenko, P. Festy, J. Gaymu, N. L. Bouteillec, S. Springer (2011). Populations and Demographic Trends of European Countries, 1980-2010 // Population-E. 66(1): 9-130.

Beaujot R. (2003). Effect of Immigration on the Canadian Population: Replacement Migration? // Discussion Papers Series. 03-03. Population Studies Centre. University of Western Ontario. London. URL: http://www.ssc.uwo.ca/sociology/popstudies/dp/dp03-03.pdf.

Bijak J., D. Kupiszewska, M. Kupiszewski, K. Saczuk, A. Kicinger (2007). Population and labour force projections for 27 European countries, 2002-052: impact of international migration on population ageing // European Journal of Population. 23(1): 1-31.

Billari F.C., G. Dalla Zuanna (2011). Is replacement migration actually taking place in low fertility countries? // Genus. 67(3): 105-123.

Calot G., J.P. Sardon (2001). Fécondité, reproduction et remplacement // Population. 56(3): 371396.

Castles S. (2004). Why migration policies fail // Ethnic and Racial Studies. 27(2): 205-227. 
Coale A. J. (1986). Demographic Effects of Below-Replacement Fertility and Their Social Implications // Population and Development Review. 12: 203-216.

Coleman D. (2001). Replacement migration, or why everyone is going to have to live in Korea: A fable for our times from the United Nations // Philosophical Transactions of the Royal Society B. 357: 583-598.

Coleman D. (2006). Immigration and Ethnic Change in Low-Fertility Countries: A Third Demographic Transition // Population and Development Review. 32(3): 401-446.

Coleman D. (2009). Introduction: migration and its consequences in 21st century Europe // Vienna Yearbook of Population Research. 1-18.

Daguet F. (2002). Le remplacement des generations // Un Siècle de Fécondité Française: Caractéristiques et Evolution de la Fécondité de 1901 á 1999. Paris: INSEE: 235-252.

Dalla Zuanna G. (2006). Population replacement, social mobility and development in Italy in the twentieth century // Journal of Modern Italian Studies. 11(2): 188-208.

Dalla Zuanna G. (2008). La misura RM del rimpiazzo delle generazioni // Popolazione e Storia. 2: $61-72$.

del Rey Poveda A., M. Cebrán-Villar (2010). Population replacement and migration in two Spanish regions during the Twentieth century // Population-E. 65(3): 481-497.

Demeny P. (2003). Population Policy Dilemmas in Europe at the Dawn of the Twenty-First Century // Population and Development Review. 29(1): 1-28.

De Santis G. (2011). Can immigration solve the aging problem in Italy? Not really.... // Genus. 57(3): 37-64.

Ediev D., D. Coleman, S. Scherbov (2007). Migration as a factor of population reproduction // European Demographic Research Papers. 1. Vienna Inst. of Demography.

URL: http://www.oeaw.ac.at/vid/download/edrp_1_07.pdf.

Ediev D., S. Scherbov, D. Coleman (2012). New measures of population reproduction for an era of high migration. Unpublished manuscript under review.

Espenshade T.J., L.F. Bouvier, W.B. Arthur (1982). Immigration and the Stable Population Model // Demography. 19(1): 125-133.

Espenshade T.J. (1986). Population Dynamics with Immigration and Low Fertility // Population and Development Review. 12: 248-261.

Espenshade T.J. (2001). "Replacement Migration” from the Perspective of Equilibrium Stationary Populations // Population and Environment. 22(4): 383-389.

European Commission (2005). Confronting demographic change: a new solidarity between the generations. Green Paper. Brussels: Commission of the European Communities.

Eurostat (2005). EU25 population rises until 2025, then falls // Eurostat news release. 48.

Eurostat (2006). Long-term population projections at national level // Eurostat news release. 3. Luxembourg: European Communities.

Eurostat (2008). Ageing characterises the demographic perspectives of the European societies // Statistics in Focus, Population and Social Conditions. 72/ Luxembourg: European Communities.

Eurostat (2011a). EU 27 population is expected to peak by around 2040 // Eurostat news release. 80. 
Eurostat (2011b). Migrants in Europe, 2011 edition. A Statistical Portrait of the First and Second Generation / Eurostat Statistical Books. Luxembourg: Publications Office of the European Union

Eurostat (2012). Population on 1 January by age and sex. URL: http://epp.eurostat.ec.europa.eu/portal/page/portal/statistics/search_database (дата обращения: 03.05. 2012).

Festy P. (1979). La fécondité des pays occidentaux 1870-1970. Présentation d'un cahier de l'INED // Cahier de l'INED. 85. Paris: Presses Universitaires de France.

Gauthier A. (2007). The impact of family policies on fertility in industrialized countries: a review of the literature // Population Research and Policy Review. 26: 232-346.

Gesano G., S. Strozza (2011). Foreign migrations and population aging in Italy // Genus. 57(3): 83-104.

Human Fertility Database (2012). Data on fertility rates in Sweden. URL: http://www.humanfertility.org. (дата обращения: 03.05. 2012).

Human Mortality Database (2012a). Data on female population and mortality tables by age in Sweden. URL: http://www.mortality.org/. (дата обращения: 03.05. 2012).

Human Mortality Database (2012b). Data on female population in Ireland. URL: http://www.mortality.org. (дата обращения: 03.05. 2012).

Hyrenius H. (1951). Reproduction and Replacement: A methodological study of Swedish population changes during 200 years // Population Studies. 4(4): 421-431.

Keely C. (2001). Replacement Migration: the wave of the future? // International Migration. 39(6): 103-110.

Kuczynski R.R. (1928). The balance of births and deaths. Vol. 1. Western and Northern Europe. New York: The MacMillan Company. The Brookings Institution.

Lesthaeghe R. (2000). Europe's demographic issues: Fertility, household formation and replacement migration // Population Studies in Britain and in the Netherlands, Utrecht.

Lutz W., S. Scherbov (2003). Future demographic change in Europe: the contribution of migration // Interim Report № IR-03-66. Laxenburg, Austria: International Institute for Applied Systems Analysis. URL: http://www.iiasa.ac.at/Admin/PUB/Documents/ IR-03066.pdf.

Mcdonald P. (2002). Sustaining Fertility through Public Policy: The Range of Options // Population-E. 57(3): 417-446.

Office for National Statistics (2010). URL: http://www.statistics.gov.uk/statbase/Product. asp?vlnk=15106 (дата обращения: декабрь 2009 - август 2010).

Oláh L.S., E.M. Bernhardt (2008). Sweden: Combining childbearing and gender equality // Demographic Research. Vol.19. Article 28. URL: http://www.demographicresearch.org/volumes/vol19/28/19-28.pdf.

Ortega J.A., L.A. del Rey Poveda (2007). Birth replacement ratios in Europe: A new look at period replacement / Annual Meeting of the Population Association of America, New York.

Preston S.H., H. Wang (2007). Intrinsic Growth Rates and Net Reproduction Rates in the Presence of Migration // Population and Development Review. 33(4): 657-666.

Ryder N.B. (1997). Migration and Population Replacement // Canadian Studies in Population. 24(1): $1-26$. 
Saczuk K. (2003). A Development and Critique of the Concept of Replacement Migration // CEFMR Working Paper. 4. Central European Forum for Migration Research. Warsaw. URL: http://www.cefmr.pan.pl/docs/cefmr_wp_2003_04.pdf.

Smallwood S., J. Chamberlain (2005). Replacement fertility, what has it been and what does it mean? // Population Trends. 119: 16-27.

Sobotka T. (2008a). Does persistent low fertility threaten the future of European populations? / P. Deboosere, J. Surkyn, J. van Bavel, eds. Demographic Challenges for the 21st Century: A State of the Art in Demography. Brussels: VUB Press: 27-89.

Sobotka T. (2008b). The rising importance of migrants for childbearing in Europe // Demographic Research. Special Collection 7. Vol. 19 (Article 9): 225-248.

Sobotka T. (2009). Migration continent Europe. Vienna Yearbook of Population Research, 2009: 217-233.

Tarmann A. (2000). The flap over replacement migration. URL: http://www.prb.org/Articles/2000/TheFlapOverReplacementMigration.aspx (дата обращения: 04. 2012).

Teitelbaum M.S., J.M. Winter (1985). The Fear of Population Decline. Orlando: Academic Press.

Tietelbaum M.S. (2004). Western experiences with international migration in the context of population decline // Japanese Journal of Population. 2(1): 29-40.

United Nations (2000). Replacement Migration: Is it a Solution to Declining and Ageing Populations? New York: Population Division.

Vatican (2006). Address of His Holiness Benedict XVI to the Roman Curia offering them his Christmas greetings. URL:

http://www.vatican.va/holy_father/benedict_xvi/speeches/2006/december/documents/hf_ben _xvi_spe_20061222_curia-romana_en.html.

VID (2012). European Demographic Data Sheet 2012. Vienna Institute of Demography and IIASA / Wittgenstein Centre for Demography and Global Human Capital. URL: http://www.oeaw. ac.at/vid/datasheet/index.html.

Vos A.E. (2009). Falling fertility rates: new challenges to the European welfare state // SocioEconomic Review. 7(3): 485-503.

Wilson C., T. Sobotka, L. Williamson., P. Boyle (2010). A simple method for estimating intergenerational replacement based on fertility and migration - European examples // ESRC Centre for Population Change. Working Paper. 10. URL: http://www.cpc. ac.uk/publications/.

Wilson C., L. Williamson (2011). Intergenerational replacement and migration in the countries and regions of the United Kingdom, 1971-2009 // Population Trends. 145(Autumn): 1-16. 